\title{
Explanation and Elaboration of the Standards of Reporting of Neurological Disorders Checklist: A Guideline for the Reporting of Incidence and Prevalence Studies in Neuroepidemiology
}

\author{
Derrick A. Bennett $^{a} \quad$ Carol Brayne ${ }^{e}$ Valery L. Feigin ${ }^{f} \quad$ Suzanne Barker-Collo ${ }^{g}$ \\ Michael Brainin ${ }^{\mathrm{h}}$ Daniel Davis ${ }^{c}$ Valentina Gallo ${ }^{\mathrm{d}}$ Nathalie Jettéi André Karch ${ }^{\mathrm{k}}$ \\ John F. Kurtzke ${ }^{m}$ Pablo M. Lavados ${ }^{n} \quad$ Giancarlo Logroscino $^{\circ} \quad$ Gabriele Nagel $^{1}$ \\ Pierre-Marie Preux $^{p} \quad$ Peter M. Rothwell ${ }^{b} \quad$ Lawrence W. Svenson $^{j}$ \\ ${ }^{a}$ Nuffield Department of Population Health and ${ }^{b}$ Stroke Prevention Research Unit, University of Oxford, Oxford, ${ }^{\mathrm{C} F a c u l t y}$ \\ of Population Health Sciences, University College London and d Centre of Primary Care and Public Health, Blizard Institute, \\ Queen Mary, University of London, London, and 'Department of Public Health and Primary Care, University of Cambridge, \\ Cambridge, UK; ${ }^{f}$ National Institute for Stroke and Applied Neurosciences, AUT University and ${ }^{9}$ Department of Psychology, \\ University of Auckland, Auckland, New Zealand; ${ }^{\text {h }}$ Department for Clinical Medicine and Preventive Medicine, Danube- \\ University, Krems, Austria; 'Department of Clinical Neurosciences and Hotchkiss Brain Institute, Department of Community \\ Health Sciences and O'Brien Institute for Public Health, University of Calgary, Calgary, Alta., and 'School of Public Health, \\ University of Alberta, Edmonton, Alta., Canada; ${ }^{k}$ Research Group Epidemiological and Statistical Methods, Helmholtz Centre \\ for Infection Research, Braunschweig, and 'Institute of Epidemiology and Medical Biometry, University of Ulm, Ulm, Germany; \\ ${ }^{m}$ Department of Neurology, Georgetown University, Washington, D.C., USA; ${ }^{n}$ Vascular Neurology and Stroke Unit, Neurology \\ Service, Department of Medicine, Clínica Alemana de Santiago, Universidad del Desarrollo and Department of Neurological \\ Sciences, Universidad de Chile, Institute of Neurosurgery, Santiago, Chile; ${ }^{\circ}$ Neurodegenerative Diseases Unit, Department of \\ Basic Medicine, Neurosciences and Sense Organs, University Aldo Moro and Department of Clinical Research in Neurology

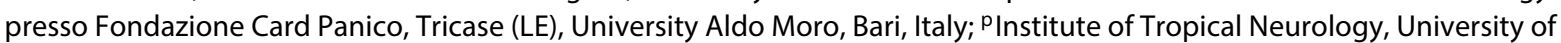 \\ Limoges, Limoges, France
}

\section{Key Words}

Neuroepidemiology $\cdot$ Incidence $\cdot$ Prevalence $\cdot$ Reporting quality · Guideline

\begin{abstract}
Background: Incidence and prevalence studies of neurological disorders play an extremely important role in hypothesis-generation, assessing the burden of disease and planning of health services. However, the assessment of disease estimates is hindered by the poor quality of reporting for
\end{abstract}


such studies. We developed the Standards of Reporting of Neurological Disorders (STROND) guideline in order to improve the quality of reporting of neurological disorders from which prevalence, incidence, and outcomes can be extracted for greater generalisability. Methods: The guideline was developed using a 3-round Delphi technique in order to identify the 'basic minimum items' important for reporting, as well as some additional 'ideal reporting items.' An e-consultation process was then used in order to gauge opinion by external neuroepidemiological experts on the appropriateness of the items included in the checklist. Findings: The resultant 15 items checklist and accompanying recommendations were developed using a similar process and structured in a similar manner to the Strengthening of the Reporting of Observational Studies in Epidemiology checklist for ease of use. This paper presents the STROND checklist with an explanation and elaboration for each item, as well as examples of good reporting from the neuroepidemiological literature. Conclusions: The introduction and use of the STROND checklist should lead to more consistent, transparent and contextualised reporting of descriptive neuroepidemiological studies that should facilitate international comparisons, and lead to more accessible information for multiple stakeholders, ultimately supporting better healthcare decisions for neurological disorders. @ $2015 \mathrm{~S}$. Karger AG, Basel

\section{Background and Rationale}

Publication of scientific research is important, as publishing research findings are the primary means of disseminating discoveries to the broader research community and other stakeholders. Lack of clarity in the reporting of a study's findings and conduct can impede the critical appraisal of the study and reduce its impact. Poor reporting of medical research also increases the risk of inadequate and potentially misleading information being utilised by important stakeholders (e.g. patients, healthcare providers and health policy makers), when making decisions. As a consequence, patients may be exposed to unnecessary risks and healthcare resources may be inappropriately allocated [1]. There is a large amount of evidence to support the fact that published medical research reports, in several fields, are often reported poorly [2-7]. Although observational studies are lower down the hierarchy of evidence than randomised controlled trials, if the best available evidence is from observational data, it can influence clinical practice. Thus, it is important that observational studies be reported clearly and systematically [8]. At the first International Congress on Clinical Neuroepidemiology that took place in Munich in August 2009, an open discussion among a panel of experienced researchers described approaches to 'bridge the gap' between neuroepidemiological research and practice. One of the key themes that emerged was that there were issues with the reporting of neurological research and this was a reason for gaps between evidence and practice for both clinicians and health policy decision makers [9].

The most common type of health policy research seeks to describe or characterise health and healthcare delivery across an entire population or system of care within subpopulations. This type of policy research is critical in the evaluation of any healthcare delivery system, examining how the system is functioning for patients, clinicians or hospitals and identifying problems or opportunities to improve healthcare delivery. A recent survey from Australia that explored the views and practices of policy makers found that making research findings more accessible to policy makers and increasing the relevance of research to policy were two important strategies for improving the integration of research into the policy process [10]. One means of accomplishing this is to ensure that descriptive epidemiological research is reported adequately. Descriptive epidemiological studies are vital for estimating prevalence, incidence, morbidity and mortality for studies, where global health is of primary concern [11]. Information from such studies may be used to quantify levels of disability and to compute disability adjusted life years (DALY) and quality adjusted life years. DALY and quality adjusted life years type metrics are particularly useful for Global Burden of Disease and Injuries (GBD) type studies [12-15] and are particularly important in health policy research, as they are relevant to patients, providers and payers; they are important also because they allow some kind of value and importance to be determined [16]. Neurological diseases such as stroke, Alzheimer's disease (AD) and other dementias are becoming more prevalent as the world's population ages [17], and are major causes of disability [18]. It is well known that the management of chronic disease involves multiple international stakeholders across multiple settings, and that there have already been important modifications in international health programming and policy that have changed the incidence, prevalence and severity of neurologic disease [19]. However, the conduct of future health policy research in these types of neurological disorders has been hampered by poor reporting of key information $[20,21]$. Typically, GBD type studies and other similar 
types of health policy research are reliant on the best data available to them. Often key information is not collected or is not reported adequately, which can severely limit potential insights that could be obtained from the work [16].

When compared to studying the epidemiology of other non-communicable diseases, neurological conditions can provide particular challenges because gold standard diagnostic tools are not available for every condition, and sometimes diagnosis requires sophisticated technology that may not be available everywhere. There can also be considerable heterogeneity in latency periods between the start of the neuropathological process and manifestation of symptoms. We aimed to develop a reporting guideline for clinical studies, case series and all research from which generalisable population data might be derived. This information is extremely important for the conduct of descriptive health policy research, such as GBD type studies [22], which can be hampered, because reporting quality of these types of studies for neurological disorders is generally poor [23]. The primary objective was to develop reporting guidance for incidence and prevalence studies specifically related to neurological disorders.

\section{Methods for Developing of the Standards of Reporting of Neurological Disorders Reporting Guideline}

The methods for the development of the Standards of Reporting of Neurological Disorders (STROND) reporting guideline have been described in detail elsewhere [24]. In brief, we conducted a consensus process in 3 phases. In the first phase, a literature review was conducted to identify consensus reports and published reporting guidelines. In the second phase of the development of the checklist, a 3-round Delphi process was conducted using a group of volunteers that had expertise in neuroepidemiological research (that were not members of the STROND group). In the third and final phase of the process, a group of independent international experts on neurological disorders (as nominated by members of the STROND collaborative group), was contacted as part of a further e-consultation process in order to assess their views on the contents of the checklist (i.e. this served as a pilot exercise). Once this 3-phase consensus process was complete, a 'final checklist' was produced based on the feedback received from all the individuals who had participated.

Explanation and Elaboration of the STROND Checklist

\section{Aims and Scope of the STROND Reporting Guideline}

The primary target audience for this reporting guideline is authors of studies of neurological disorders, prevalence, incidence, and clinical studies in primary, secondary and tertiary care settings including cohorts or case series with follow-up from which generalisability could be inferred if provenance is known, and the editors and peer reviewers of the journals in which they intend to publish. The main goal of the guideline, which consists of 15 recommendations outlining the basic minimum amount of reported information required' as well as 'ideal reporting information' in the form of a checklist, is to provide a useful and practical tool for this audience. The ultimate goal is to improve reporting and, in turn, health and healthcare decisions. The accompanying examples and explanations in this report are intended to facilitate understanding and application of the recommendations. The STROND reporting guideline assumes that the amount of information required for 'ideal reporting' will generally exceed the conventional space limits of most journals. Therefore, recommendations are made assuming authors and journals will make information available to readers using their online appendices and other means if this is required.

\section{The STROND Checklist Items}

We now discuss and explain the 15 items in the STROND checklist (table 1), and give published examples of good reporting for each item.

We have denoted 'basic reporting items' in regular font and 'ideal reporting items' in bold font in order to distinguish between them. The final recommendations are subdivided into 5 main categories: (1) title and abstract; (2) introduction; (3) methods; (4) results; (5) discussion. The following section provides specific examples of good reporting for each item of the STROND checklist along with an explanation that highlights the need for the item and some additional guidance for authors about fulfilling the recommendation requirements. For some of the examples of 'good reporting' included, we edited the text by removing citations or spelling out abbreviations in full. We provide the details of references for the published studies that have been used as examples of good reporting for a particular item on the checklist in table 2 rather than in the main text. It should not be inferred that because we used a particular example that all aspects of the study were well reported.

Neuroepidemiology 2015;45:113-137 115 
Table 1. STROND: a guideline for the reporting of incidence and prevalence studies in neuroepidemiology

\begin{tabular}{|c|c|c|}
\hline Section/topic & Number & Recommendation \\
\hline \multirow[t]{2}{*}{$\begin{array}{l}\text { Title and abstract } \\
\text { Title and abstract }\end{array}$} & $1 \mathrm{a}$ & Give the type of study design employed using a widely recognised term in the title or abstract \\
\hline & $1 \mathrm{~b}$ & $\begin{array}{l}\text { The abstract should give an accurate summary of how the study was conducted and the main } \\
\text { findings }\end{array}$ \\
\hline \multicolumn{3}{|l|}{ Introduction } \\
\hline Background & 2 & Details of the scientific rationale for the study should be reported \\
\hline Aims and objectives & 3 & State the specific aims and objectives of the study \\
\hline \multicolumn{3}{|l|}{ Methods } \\
\hline \multirow[t]{3}{*}{ Study design } & 4 & Give a full description of the study design \\
\hline & $4 a$ & $\begin{array}{l}\text { Give details of any study protocol (published or unpublished that gives additional useful } \\
\text { information on the study design) }\end{array}$ \\
\hline & $4 \mathbf{b}$ & $\begin{array}{l}\text { If a pilot study has been conducted to inform the main study design then the findings } \\
\text { should be referenced }\end{array}$ \\
\hline Setting & 5 & $\begin{array}{l}\text { Clearly defined (usually, but not always, on a geographic basis), and stable, with reliable infor- } \\
\text { mation on in- and out-migration }\end{array}$ \\
\hline \multirow[t]{7}{*}{ Source population } & 6 & $\begin{array}{l}\text { Description of how all eligible members of the population will be identified and through what } \\
\text { data sources (e.g. hospitals, outpatient clinics, death certificates) }\end{array}$ \\
\hline & $6 a$ & (i) Source of data used for the study (e.g. administrative database, medical records). \\
\hline & & (ii) If administrative database used algorithms for data extraction should be described \\
\hline & $\mathbf{6 b}$ & $\begin{array}{l}\text { Description of the rate of hospital admission (if applicable) for the neurological condition } \\
\text { in the population }\end{array}$ \\
\hline & $6 c$ & $\begin{array}{l}\text { Details of health care system in the country (study region) where the study was conducted } \\
\text { (e.g. public versus private health care system) }\end{array}$ \\
\hline & 6d & $\begin{array}{l}\text { Description of how a person with the neurological condition is referred (with the filters) in } \\
\text { the country (study region) where the study was conducted }\end{array}$ \\
\hline & $6 e$ & $\begin{array}{l}\text { Description and characteristics of (i) response rate/drop outs and } \\
\text { (ii) exclusion rate if applicable }\end{array}$ \\
\hline \multirow[t]{7}{*}{ Participants } & 7 & $\begin{array}{l}\text { Definition of cases is clearly defined and consistent with and the criteria used are clearly } \\
\text { described and in sufficient detail }\end{array}$ \\
\hline & $7 \mathrm{a}$ & $\begin{array}{l}\text { Details of the sampling method are described (are participants } \\
\text { representative of the source population) }\end{array}$ \\
\hline & $7 \mathrm{~b}$ & Fully validated source of diagnosis or 'reference-standard' criteria applied \\
\hline & $7 \mathrm{c}$ & $\begin{array}{l}\text { Definition and justification of the disease severity (preferably using a standardized } \\
\text { severity scale) or staging of the disease }\end{array}$ \\
\hline & $7 \mathrm{~d}$ & $\begin{array}{l}\text { Description of how types/subtypes of the neurological disorder of interest are } \\
\text { distinguished (if relevant) }\end{array}$ \\
\hline & $7 \mathrm{e}$ & Description of how completeness of case-ascertainment was assessed \\
\hline & $7 f$ & Description of whether completeness of case ascertainment was adequate \\
\hline Ethical approval & 8 & Details of ethical approval/informed consent/data governance should be reported \\
\hline Measurement & $9 \mathrm{a}$ & $\begin{array}{l}\text { Incidence studies } \\
\text { (i) Give details of how incidence was determined (based on timing of data collection } \\
\text { either prospectively or retrospectively) }\end{array}$ \\
\hline
\end{tabular}


Table 1. (continued)

\begin{tabular}{|c|c|c|}
\hline Section/topic & Number & Recommendation \\
\hline & & (ii) Definition and justification of timing of measurements \\
\hline & & (iii) The data presented to some specified time period (usually whole years or person-time) \\
\hline & & $\begin{array}{l}\text { (iv) Raw numbers are reported in sufficient detail (tables, figures or main text), to } \\
\text { calculate the appropriate rates (e.g. by age or gender) }\end{array}$ \\
\hline & $9 \mathrm{~b}$ & $\begin{array}{l}\text { Prevalence studies } \\
\text { (i) Give details of specific time points over which estimates are derived (usually defined as the } \\
\text { number of cases existing in a specific time point) }\end{array}$ \\
\hline & & (ii) The data presented to some specified time period (usually whole years) \\
\hline & & $\begin{array}{l}\text { (iii) Raw numbers are reported in sufficient detail (tables, figures or main text), to calculate the } \\
\text { appropriate rates (e.g. by age or gender) }\end{array}$ \\
\hline & 9c & $\begin{array}{l}\text { If disease burden is to be assessed the study should report details of burden due to a } \\
\text { variety of sources (e.g. disability, DALYs, symptoms, financial, caregiver, etc.) }\end{array}$ \\
\hline & 9d & Report any arrangements for quality checks/data verification/triangulation \\
\hline & $9 e$ & Report details of the training of the person administering the instruments \\
\hline \multirow[t]{6}{*}{ Statistical methods } & 10 & $\begin{array}{l}\text { If rates have been standardised (e.g. by age or gender), then the details of the standard } \\
\text { population used should be given }\end{array}$ \\
\hline & $10 \mathrm{a}$ & $\begin{array}{l}\text { If possible } 2 \text { standard populations should be used one with local relevance and the other to } \\
\text { facilitate international comparisons }\end{array}$ \\
\hline & $10 \mathrm{~b}$ & Description of any assumptions made in the calculations should be reported \\
\hline & $10 \mathrm{c}$ & An explanation of how missing data was addressed in the analyses \\
\hline & 10d & $\begin{array}{l}\text { Provide a priori estimates of: sample size/power assessment/precision of estimates } \\
\text { assessment }\end{array}$ \\
\hline & $10 \mathrm{e}$ & Description of any sensitivity analyses \\
\hline
\end{tabular}

Results

11 Consider a flow diagram that describes how participants were included in the study (useful to assess of how a person with the neurological condition of interest is referred (with the filters))

\begin{tabular}{ll}
\hline $11 \mathrm{a}$ & Give appropriate rates with their associated 95\% CIs \\
\hline $11 \mathrm{~b}$ & Report results of any sensitivity analyses
\end{tabular}

\begin{tabular}{lll}
\hline $\begin{array}{l}\text { Discussion } \\
\text { Key findings }\end{array}$ & 12 & Summarise the key findings in relation to the study aims and objectives \\
\hline \begin{tabular}{ll} 
Limitations \\
\cline { 2 - 3 }
\end{tabular} & 13 & $\begin{array}{l}\text { Discuss potential limitations of the study } \\
\text { Include details of risk of bias (e.g. selection bias), completeness of case ascertainment, and } \\
\text { data quality (assessment of its probability, size and potential importance) }\end{array}$ \\
\hline $\begin{array}{ll}\text { Interpretation } \\
14 \mathrm{a}\end{array}$ & $\begin{array}{l}\text { Interpret the results in the context of the evidence from other well performed studies with simi- } \\
\text { lar designs and objectives }\end{array}$ \\
\hline $\begin{array}{l}\text { Reliability of the estimates (i.e. based on the reporting of the statistical methodology, and study } \\
\text { design, measurement of key information) }\end{array}$ \\
\hline 15 & $\begin{array}{l}\text { Discuss the external validity of the study findings } \\
\text { Generalisability }\end{array}$ & $\begin{array}{l}\text { Are the results consistent with meta-analyses of descriptive } \\
\text { epidemiological studies on the same topic that cover different settings (if applicable)? }\end{array}$ \\
\hline
\end{tabular}


Table 2. Examples for the published literature of good reporting of each item included in STROND checklist

\begin{tabular}{|c|c|c|}
\hline Section/topic & Number & Reference for the example of good reporting used \\
\hline \multirow[t]{2}{*}{$\begin{array}{l}\text { Title and abstract } \\
\text { Title and abstract }\end{array}$} & $1 \mathrm{a}$ & Darin N, et al: Neuromuscul Disord 2000;10:1-9 \\
\hline & $1 b$ & Bazarian J, et al: Brain Inj 2005;19:85-91 \\
\hline \multicolumn{3}{|l|}{ Introduction } \\
\hline Background & 2 & Hagen E-M, et al: Spinal Cord 2010;48:313-318 \\
\hline Aims and objectives & 3 & Hagen E-M, et al: Spinal Cord 2010;48:313-318 \\
\hline \multicolumn{3}{|l|}{ Methods } \\
\hline \multirow[t]{3}{*}{ Study design } & 4 & $\begin{array}{l}\text { Siqueiraa HH, et al: UNOPAR Cient Ciênc Biol Saúde } \\
\text { 2014;16:107-111 }\end{array}$ \\
\hline & $4 a$ & de Jesús Llibre J, et al: MEDICC Rev 2010;12:20-26 \\
\hline & $4 \mathrm{~b}$ & $\begin{array}{l}\text { Cabral NL, et al: J Neurol Neurosurg Psychiatry } \\
\text { 2009;80:755-761 }\end{array}$ \\
\hline Setting & 5 & Marrie RA, et al: Neurology 2010;74:465-471 \\
\hline \multirow[t]{7}{*}{ Source population } & 6 & Darin N, et al: Neuromuscul Disord 2000;10:1-9 \\
\hline & \multirow[t]{2}{*}{$6 \mathrm{a}$} & (i) Lenehan B, et al: Spine 2012;37:321-329 \\
\hline & & (ii) Noyes K, et al: Mov Disord 2007;22:509-514 \\
\hline & $\mathbf{6 b}$ & Calderón-Larrañagaa A, et al: Seizure 2014;23:657-661 \\
\hline & $6 c$ & $\begin{array}{l}\text { Cabral NL, et al: J Neurol Neurosurg Psychiatry } \\
\text { 2009;80:755-761 }\end{array}$ \\
\hline & $6 d$ & Azharpazhooh MR, et al: Stroke 2010;41:e3-e10 \\
\hline & $6 e$ & $\begin{array}{l}\text { (i) Jungehulsing GJ, et al: Neuroepidemiology } \\
\text { 2008;30:50-57 }\end{array}$ \\
\hline
\end{tabular}

(ii) Nicolletti A, et al: Stroke 2000;31:882-885

\begin{tabular}{|c|c|c|}
\hline \multirow[t]{7}{*}{ Participants } & 7 & Melcon C, Melcon M: Neuroepidemiology 2006;27:81-88 \\
\hline & $7 \mathrm{a}$ & Gavrila D, et al: Acta Neurol Scand 2009;120:300-307 \\
\hline & $7 \mathrm{~b}$ & Lavados P, et al: Lancet Neurol 2007;6:140-148 \\
\hline & $7 \mathrm{c}$ & de Lau LM, et al: Neurology 2004;63:1240-1244 \\
\hline & $7 \mathrm{~d}$ & Lavados P, et al: Lancet Neurol 2007;6:140-148 \\
\hline & $7 \mathrm{e}$ & Thrift A, et al: Neuroepidemiology 2009;32:11-18 \\
\hline & $7 \mathrm{f}$ & Marin B, et al: Eur J Neurol 2014;21:1292-1300 \\
\hline Ethical approval & 8 & de Jesús Llibre J, et al: MEDICC Rev 2010;12:20-26 \\
\hline \multirow[t]{5}{*}{ Measurement } & $9 \mathrm{a}$ & Incidence studies \\
\hline & & (i) Olafsson E, et al: Lancet Neurol 2005;4:627-634 \\
\hline & & (ii) Alzamora, et al: BMC Neurol 2008;8:5 \\
\hline & & $\begin{array}{l}\text { (iii) Al-Asmari A, et al: Disabil Rehabil 2006;28:1373- } \\
1377\end{array}$ \\
\hline & & (iv) Alzamora MT, et al: BMC Neurol 2008;8:5 \\
\hline
\end{tabular}


Table 2. (continued)

\begin{tabular}{|c|c|c|}
\hline Section/topic & Number & Reference for the example of good reporting used \\
\hline & \multirow[t]{4}{*}{$9 b$} & Prevalence studies \\
\hline & & (i) Lipton RB, et al: Neurology 2007;68:343-349 \\
\hline & & (ii) Marrie RA, et al: Neurology 2010;74:465-471 \\
\hline & & (iii) Aarsland D: Arch Neurol 2003;60:387-392 \\
\hline & 9c & Landfelt E, et al: Neurology 2014;83:529-536 \\
\hline & 9d & MacDonald BK, et al: Brain 2000;123:665-676 \\
\hline & $9 e$ & de Jesús Llibre J, et al: MEDICC Rev 2010;12:20-26 \\
\hline \multirow[t]{6}{*}{ Statistical methods } & 10 & Danesi M, et al: Neuroepidemiology 2007;28:216-223 \\
\hline & $10 a$ & Mathuranath $P$, et al: Neurol India 2012;60:625-630 \\
\hline & $10 \mathrm{~b}$ & Stewart W, et al: Cephalalgia 2008;28:1170-1178 \\
\hline & $10 c$ & Luengo-Fernandez R, et al: Neurology 2013;81:1588-1595 \\
\hline & 10d & Kamran Kamal A, et al: BMC Neurol 2009;9:58 \\
\hline & $10 \mathrm{e}$ & Fitzpatrick AL, et al: J Am Geriatr Soc 2004;52:195-204 \\
\hline \multicolumn{3}{|l|}{ Results } \\
\hline & 11 & Mustapha AF, et al: Epilepsy Behav 2014;37:258-264 \\
\hline & $11 \mathrm{a}$ & Adoukonou T, et al: World J Neurosci 2014;4:18-24 \\
\hline & $11 \mathrm{~b}$ & Fitzpatrick AL, et al: J Am Geriatr Soc 2004;52:195-204 \\
\hline \multicolumn{3}{|l|}{ Discussion } \\
\hline \multirow[t]{2}{*}{ Limitations } & 13 & Bazarian J, et al: Brain Inj 2005;19:85-91 \\
\hline & $13 \mathbf{a}$ & Vaartjes I, et al: Eur J Neurol 2008;15:1315-1323 \\
\hline \multirow[t]{2}{*}{ Interpretation } & 14 & Sacco S, et al: Eur J Neurol 2009;62:155-160 \\
\hline & $14 \mathrm{a}$ & Vaartjes I: Eur J Neurol 2008;15:1315-1323 \\
\hline \multirow[t]{2}{*}{ Generalisability } & 15 & Alonso A, et al: Eur J Neurol 2009;16:745-751 \\
\hline & $15 \mathrm{a}$ & Das SK, et al: Indian J Med Res 2006;124:163-172 \\
\hline
\end{tabular}

\section{The Title and Abstract Section of the Report}

\section{1 (a) Basic Minimum Required Recommendation:}

Give the Type of Study Design Employed Using a Widely Recognised Term in the Title or Keywords in the Abstract

\section{Example}

Title: 'Neuromuscular disorders in childhood: a descriptive epidemiological study from western Sweden.'

Keywords: 'Epidemiology; Neuromuscular disorders; Incidence; Prevalence; Spinal muscular atrophy; Muscular dystrophy; Myopathy; Neuropathy; Childhood.'

Explanation and Elaboration of the STROND Checklist

\section{Explanation}

There are currently millions of research articles published each year that are indexed in electronic databases such as Medline and PubMed. These databases contain journal citations and abstracts for the biomedical literature for all corners of the globe that are indexed with varying degrees of detail. If titles are clear and precise and use certain keywords, there is a greater likelihood that these papers will be catalogued using these terms and thus easier to locate. Vague and ambiguous titles run the risk of being inappropriately indexed making identification more difficult when databases are being searched for incidence and prevalence studies of neurological disorders. 
1 (b) Basic Minimum Required Recommendation: The Abstract Should Give an Accurate Summary of How the Study Was Conducted and the Main Findings

\section{Example}

'Primary objective: To determine the incidence and epidemiology of emergency department (ED)-attended mild traumatic brain injury (mTBI) in the United States. Research design: Secondary analysis of ED visits for mTBI in the National Hospital Ambulatory Medical Care Survey for 1998-2000. Methods and procedures: mTBI defined by International Classification of Diseases, 9th Revision, Clinical Modification (ICD-9-CM) codes for 'skull fracture', 'concussion', 'intracranial injury of unspecified nature' and 'head injury, unspecified'. Main outcome and results: The average incidence of mTBI was 503.1/100,000, with peaks among males (590/100,000), American Indians/Alaska Natives $(1,026 / 100,000)$ and those $<5$ years of age $(1,115 \cdot 2 / 100,000)$. mTBI incidence was highest in the Midwest region $(578.4 / 10,000)$ and in non-urban areas $(530.9 / 100,000)$ of the United States. Bicycles and sports accounted for $26.4 \%$ of mTBI in the 5-14 age group. Conclusions: The national burden of $\mathrm{mTBI}$ is significant and its incidence higher than that reported by others. Possible explanations are discussed. Bicycle- and sports-related injuries are an important and highly preventable cause of mTBI underscoring the need to promote prevention programmes on a national level.'

\section{Explanation}

We recommend the use of structured abstracts when reporting the details of incidence or prevalence studies of neurological disorders. Structured abstracts provide readers with a series of headings pertaining to the background, aims and objectives, type of study, study population, methods, results and conclusion. One very important reason for clear and structured abstracts is that published research is not always freely available and some health professionals do not have access to full research reports; so they have no choice but to rely on the abstract for their information. The information contained in the abstract should be accurate and should be based on the main body of the text in the full report [25].

\section{The Introduction Section of the Report}

\section{Basic Minimum Required Recommendation: \\ Details of the Scientific Rationale for the Study Should Be Reported}

\section{Example}

'Traumatic spinal cord injury (TSCI) causes permanent dysfunction in several organ systems and leads to frequent complications. The condition causes life-long loss of function and reduced quality of life, and has an impact on morbidity and mortality. As there is no cure for TSCI, prevention is of paramount importance. Knowledge of incidence, prevalence and injury causes is vital for preventing and planning clinical and community services for this patient group. The yearly incidence of TSCI is listed as 9.2-57.8 per million. Comparative studies of TSCI in different regions of the world have shown large epidemiological differences. This variation may in part be caused by differences in definition, classification and procedures of patient identification, as well as differences in geography and culture.'

\section{Explanation}

The introduction section of the report should describe the basic rationale of the study and the research question that the authors aim to answer. The scientific background of the study should briefly review the topic of interest highlighting the current state of knowledge and outline any gaps in the current evidence base. The introduction should allow the reader to determine the rationale for the study as well as enable them to make a judgment on the importance of the research to the contemporary scientific literature in the topic of interest.

\section{Basic Minimum Required Recommendation: State the Specific Aims and Objectives of the Study}

Example

'In this study, we assess the prevalence and temporal trends in the incidence of TSCI, and demographic and clinical characteristics of an unselected, geographically defined cohort in the period 1952-2001.'

\section{Explanation}

The authors should outline the purpose of the study, the research question that the study aims to answer or how this study can contribute new information.

\section{The Methods Section of the Report}

\section{Basic Minimum Required Recommendation: Give a Full Description of the Study Design}

\section{Example}

'A descriptive, retrospective study was conducted to analyse outpatients series over 15 years of age between January and December 2008, at the Macarana Centre for Integrated Healthcare, which is under contract to the Barra de Bugres city council in Mato Grosso state, Brazil.'

\section{Explanation}

We recommend that a full description of the study design should be presented early in the Methods section, so that readers can fully understand the basics of the study. 
4 (a) Ideal Reporting Recommendation: Give Details

of Any Study Protocol (Published or Unpublished That

Gives Additional Useful Information on the Study

Design)

\section{Example}

'Cuba is part of the 10 of 66 study, designed to estimate the prevalence and incidence of dementia and other chronic noncommunicable diseases, including stroke, in the population aged $\geq 65$ years. The study protocol has involved 3 phases: a 2001 pilot study to validate the 10 of 66 instruments and diagnostic algorithm in 25 countries, including Cuba; a single-phase, door-todoor cross-sectional 'prevalence study' of adults aged $\geq 65$ years, carried out in Cuba in 2003-2006 with a total sample of 3,015 individuals located in catchment areas of selected communitybased polyclinics in Havana city and Matanzas provinces; and a 3-year follow-up of the cross-sectional study populations in 7 Latin American countries (including Cuba) and China with 15,000 participants, which will conclude in 2010. Details of this research protocol have been widely published.'

\section{Explanation}

A published protocol can provide important information about the study that is not covered in the published report that may be useful to the reader. Detailed information about study procedures, diagnostic criteria and study conduct may be reported in the protocol that can help the reader better understand the study.

\section{4 (b) Ideal Reporting Recommendation: If a Pilot \\ Study Has Been Conducted to Inform the Main Study \\ Design Then the Findings Should Be Referenced}

\section{Example}

'A pilot study was carried out from August to November 2004 to test the criteria and feasibility of the study procedures. We named the study Joinville vascular (JOINVASC).'

\section{Explanation}

A pilot study can be used to assess the feasibility of the study as well as to provide useful preliminary information on effect size and likely variability that could be used for statistical power calculations for the main study [26]. A pilot study can also identify the approaches that worked well and those that did not. If such a study has been conducted, the authors should reference the journal or website where the pilot study has been published (if applicable), as it can provide useful background material to the study for the reader.

\section{Basic Minimum Required Recommendation: Setting Clearly Defined (Usually, but Not Always, on a Geographic Basis), and Stable, with Reliable Information on In- and Out-Migration}

\section{Example}

'Manitoba is a central Canadian province with a stable population of nearly 1.2 million, $98 \%$ of whom receive health care coverage through the provincial government department, Manitoba Health and Healthy Living (MHHL). MHHL also maintains a population registry, which is updated when an individual moves into or out of Manitoba, changes marital or family status, or dies.'

\section{Explanation}

The readers of a manuscript need to have information on setting and locations to assess the context and generalisability of a study's results. Having knowledge of where a study took place and the size and type of the population being assessed can provide important insights and aid in the interpretation of results.

\section{Basic Minimum Required Recommendation: Description of How All Eligible Members of the Population Will Be Identified and through What Data Sources (e.g. Hospitals, Outpatient Clinics, Death Certificates)}

\section{Example}

'Residential and outpatient registers were analysed for the period 1979-1994, from local and regional paediatric hospitals, local and regional child rehabilitation centres and local and regional orthopaedic hospitals. Written enquiries were sent to all outpatient paediatric clinics in the region. Muscle biopsy registers at the Departments of Pathology, of Göteborg University and the University of Linköping were reviewed. At the beginning of the study period (1979-1983), all muscle biopsies from the region were sent to the Department of Pathology and Neurophysiology, University of Linköping. Registers at the Departments of Neurophysiology and Clinical Genetics, Göteborg University were reviewed. The National Swedish Board of Health and Welfares register of causes of death was also studied.'

\section{Explanation}

Detailed descriptions of the study participants and how they were identified can help readers of a manuscript to understand the applicability of the results. 
6 (a) Basic Minimum Required Recommendation: (i)

Source of Data Used for the Study (e.g. Administrative

Database, Medical Records)

\section{Example}

'Data on all patients admitted to Vancouver general with spinal cord injury (SCI) between 1995 and 2004 were prospectively collected using a customised, fully relational, locally designed, spine database (Vertebase). The admitting surgeons, all of whom are fellowship-trained, dedicated spine surgeons, were responsible for coding the patients' diagnoses, neurology, treatment, and complications. This was compiled by spine research coordinators and was reviewed by the surgeons at weekly peer review rounds for accuracy and completeness. Further demographic data were secondarily gathered from additional provincial resources such as the British Columbia Trauma Registry. This comprehensive data-collection system identified all cases of SCI as defined by the World Health Organization's ICD-9-CM diagnostic codes 952.x (SCI without evidence of fracture) and 806.x (fracture of vertebral column with SCI) to ensure a complete data set.'

\section{Explanation}

Detailed descriptions of the source of data used can help readers of a manuscript to understand the applicability of the results to their own setting. Clear definitions and steps taken to adhere to them will give the reader an indication of the accuracy and completeness of the data collected for the study.

\section{6 (a) Ideal Reporting Recommendation: (ii) If Administrative Database Used Algorithms for Data Extraction Should Be Described}

\section{Example}

'We identified the list of potential ICD-9 codes used for patients with Parkinsonism including ICD-9-CM 332.0, 332.1, 333.0, 333.1. Since the vast majority of Medicare beneficiaries with PD who had encounters with healthcare system in a given year saw a physician or had an outpatient visit, we examined the accuracy of physician/supplier (PHY) claims alone for identifying PD cases. In addition, we evaluated how accurately one can identify beneficiaries with $\mathrm{PD}$ using all seven types of claims combined, namely, PHY, outpatient (OUTPAT), durable medical equipment claims, inpatient hospital claims, skilled nursing facility claims, home health claims, and hospice claims.

We conducted separate analyses using ICD-9-CM 332.0 alone and using all codes together $(332.0,332.1,333.0,333.1)$ to identify Parkinsonism. Using the reference Standards A and B, we evaluated the sensitivity, specificity, and positive predictive values of the ICD-9 codes from Medicare claims for correctly identifying cases of Parkinsonism. We treated all codes similarly regardless of the field they were entered in (as principle diagnoses or not).'

\section{Explanation}

Administrative databases are now becoming much more common in both descriptive and analytical epidemiological research. These administrative databases were not necessarily designed to facilitate the conduct of research so they can be of variable quality (as the database may not have been designed, or the data been entered, by individuals with research training) [27-29]. As a consequence, it is important to know how valid and reliable the data is likely to be, what sort of catchment area does it cover, and other relevant details about the source population contained in the database [30]. Algorithms validated in adults have been demonstrated to be inaccurate for the identification of children with the same disease [31,32], and some algorithms are more sensitive for older adults compared with younger adults [33]. A recent study by Jain et al. [34] highlighted the limitations of using Medicare claims data as the main secondary source of identifying Parkinson's disease (PD) compared to PD identified via self-report or use of antiparkinsonian medications. In a systematic review, St. Germaine-Smith et al. [35] concluded that in order to ensure that population-based studies of neurological conditions that used administrative datasets were interpreted correctly, the accuracy of the case-definition should be carefully scrutinised.

\section{6 (b) Ideal Reporting Recommendation: Description of the Rate of Hospital Admission for the Neurological Condition in the Population}

\section{Example}

'Epileptic seizures are the commonest neurological complaint among people presenting acutely to hospital, accounting for $3 \%$ of all emergency presentations. A 2004 report found that in England and Wales there were about 800 deaths per year, where epilepsy was the underlying cause, and about 37,000 admissions, where epilepsy was the main diagnosis. Both mortality and hospital admission rates for epilepsy remained relatively stable during the periods examined. In North-East England, epilepsy accounted for the highest proportion of patients with 2 or more emergency admissions for the same condition in the year 2006/2007.'

\section{Explanation}

A clear description of the rate of hospital admission, and who from the local or wider populations can be admitted, for the particular neurological condition can be helpful to quantify the burden of the condition on health services and understand the biases of the 'filters' that op- 
erate between community and all other services in which individuals might be recruited. It has been reported that for some neurological conditions, such as epilepsy, the risk of admission into hospital may be reduced by improving the level of primary care [36].

\section{6 (c) Ideal Reporting Recommendation: Details of Health Care System in the Country (Study Region) Where the Study Was Conducted (e.g. Public vs. Private Health Care System)}

\section{Example}

'In the year 2000 census, the population of the city of Joinville was 429,604 inhabitants, and the projection for the year 2005 was 487,047 inhabitants. The city has 4 general hospitals and 1 public institutional care facility, totalling 840 beds. All of the hospitals, with the exception of the public institutional care facility, have CT services available on a 24 h basis.'

\section{Explanation}

Differences in the healthcare system can affect external validity. Even if the healthcare systems are similar other national differences can still affect generalisability [37]. For example, with cerebrovascular disease, there are many important differences between countries in methods of diagnosis and management $[37,38]$.

\section{6 (d) Ideal Reporting Recommendation: Description of How a Person with the Neurological Condition Is Referred (with the Filters) in the Country (Study Region) Where the Study Was Conducted}

\section{Example}

'The Mashhad Stroke Incidence Study was conducted in 3 different health districts of Mashhad, located in the province of Khorasan-Razavi, north-eastern Iran. From November 21, 2006, for a period of 1 year, patients with recent stroke in the already defined study areas were identified. The study area was delineated by the main boulevards in Mashhad. According to the 2006 census, the study population comprised 450,229 inhabitants. The only neurology centre in Mashhad is Ghaem Hospital, and all neurology emergency care is supplied at this hospital. Ghaem Hospital is 1 of the most important hospitals in the east of Iran. It is the referral hospital for eastern Iran (Khorasn, Sistan, and Baluchistan provinces) and for the region west of Afghanistan. Patients or next of kin calling the emergency services telephone number in Iran and who are identified as having a neurologic condition are transferred to Ghaem Hospital. When a patient with stroke is admitted to another hospital, after having been incorrectly diagnosed with another condition, they will then be transferred to Ghaem Hospital as soon as their diagnosis of stroke is made. This occurs when the hospital does not have a neurologist. In addition, some hospitals have a policy not to admit stroke patients because of the high associated mortality and morbidity and lengthy hospital stay. The other main hospital located in the study region is Hasheminejad Hospital, which has both internal medicine and neurosurgical wards. The 2 other smaller hospitals located within the region are 17 Sharivar (a welfare insurance hospital) and Imam Hosein (a military hospital).'

\section{Explanation}

This can be important information as the details of how a potential patient will be treated in a particular country can provide an explanation for heterogeneity in incidence and prevalence rates for particular neurological conditions based on the quality of service available [39]. This information can also be used to identify potential areas of concern for health policy makers to address when considering how to reduce the burden of a particular neurological condition in a particular country.

\section{6 (e) Basic Minimum Required Recommendation: Description and Characteristics of (i) Response Ratel Drop Outs and (ii) Exclusion Rate if Applicable}

\section{Example Response Rate}

'A total of 28,090 persons responded to the questionnaire (response rate $37.5 \%)$. Of the respondents, $43 \%$ were men with a mean $( \pm S D)$ age of $62.9 \pm 8.9$ years, and $56 \%$ were women $(65.5 \pm$ 10.2 years; table 1$)$.'

\section{Example Exclusions}

'Of the 9,955 subjects screened, 1,130 (11.3\%) were positive at the screening instrument. Of these, 1,027 were directly examined by neurologists in phase 2 . One hundred three (10\%) were not examined; of these, 86 were not found, 10 died during the study, and 7 refused the neurological examination. Of the 86 subjects not found in second phase, only 9 were aged $>50$ years.'

\section{Explanation}

The response rate can provide a good indicator of whether the participants in study were representative of the population and help the reader to determine the likely external validity of the study report [40]. It is important for readers of a manuscript to get a detailed description of the participants that were included or excluded from the study and the reasons for this. 


\section{Basic Minimum Required Recommendation: Definition of Cases Is Clearly Defined and Consistent with and the Criteria Used Are Clearly Described and in Sufficient Detail}

\section{Example}

'Stroke was defined according to the WHO criteria as: 'clearly described episode with sudden or rapid onset (1) focal brain dysfunction resulting from occlusive or haemorrhagic lesions of the vascular supply of the brain, or (2) global brain dysfunction with documentation of subarachnoid or intraventricular haemorrhage (IVH). Symptoms that persisted for over $24 \mathrm{~h}$ or that even led to death within $24 \mathrm{~h}$ with no apparent cause other than vascular origin; subdural and traumatic haemorrhages were excluded.' For the diagnosis of haemorrhagic stroke, the evidence of intraparenchymal haemorrhage, IVH, subarachnoid haemorrhage (SAH; excluding extradural and subdural hematomas and traumatic haemorrhages) had to be documented. For ischemic stroke, clinical evidence of focal brain dysfunction and absence of intraparenchymal haemorrhage, IVH and SAH had to be documented. Recurrent strokes were defined as new vascular attacks, which occur more than 3 weeks after the first-ever event. For the prevalence rate, only the first-ever episode was considered. Uncertain strokes were those that could not be classified due to insufficient information. To ascertain the type of stroke at the time of diagnosis, head $\mathrm{CT}$ and/or angiography was performed within the 2-week period after the stroke.'

\section{Explanation}

It is very important that the definition of cases is described and in sufficient detail. For many neurological disorders, the definition of a case may change over time or there is no 'gold standard criteria' available [41]. Readers of a manuscript will be able to assess if the definitions being used are similar to their own study and this will help in the interpretation of the study in the context of their own work.

\section{7 (a) Basic Minimum Required Recommendation: Details of the Sampling Method Are Described (Participants Are Representative of the Source Population)}

\section{Example}

'The sample was drawn from Murcia Regional Health Service lists, which encompass $99.4 \%$ of the population. The lists include both community dwellers and institutionalised elders. Eight primary health care centres for urban area and one for rural area were selected. A random sample of 1,500 subjects 65 years and older was drawn from the Murcia Regional Health Service lists of these 9 centres. A letter describing the study and its purpose was sent to every eligible subject. Two weeks later, subjects received a phone call and were invited for a general interview, to the primary health care centre or they were met in their own homes, based on their preference.'

\section{Explanation}

Details of how the sample was selected can help the reader to determine the applicability of the results. Some studies will use a random sample, while others may use various complex sampling schemes in order to ascertain participants [29]. This is important as the reader can use this information in order to determine whether the sample is representative of the source population or not, and what techniques have been employed to account for the complex sampling scheme.

\section{7 (b) Basic Minimum Required Recommendation: \\ Fully Validated Source of Diagnosis or \\ 'Reference-Standard' Criteria Applied}

Example

'All patients' clinical data, radiological images (CT), ECG, echocardiography, and carotid duplex results were sent to the central adjudication committee, where 2 or 3 cerebrovascular neurologists reviewed the data and categorised the patients according to pathological type, ischaemic stroke syndromes, and most probable cause, according to pre-specified definitions. All the patients were then re-reviewed by 2 different cerebrovascular neurologists who further categorised the patients by consensus to 1 of 5 possible causes on the basis of the TOAST (Trial of Org 10172 in Acute Stroke Treatment) classification and according to clinical, imaging, and cardiovascular risk factors. In cases of incomplete studies and an obvious cause $(\geq 50 \%$ stenosis in the symptomatic side in a patient without echocardiography but no atrial fibrillation on ECG, or patients with a high-risk cardioembolic source but no vascular studies), patients were grouped based on the most probable cause.'

\section{Explanation}

Using 'reference-standard' criteria can help the reader to ascertain the comparability of their study with the data reported in the manuscript. It would also be helpful if manuscripts report the findings of any previous studies of the validity or reliability the reference standard that was used [42].

\section{7 (c) Basic Minimum Required Recommendation: Definition and Justification of the Disease Severity (Preferably Using a Standardised Severity Scale) or Staging of the Disease}

\section{Example}

'At baseline and follow-up evaluation, we used a 2-phase design to identify subjects with parkinsonism or PD. In the first phase, all participants were screened at the research centre for signs of parkinsonism (e.g. resting tremor, rigidity, bradykinesia, or impaired postural reflexes) in a standardised way. Those who screened pos- 
itive received a structured clinical workup, comprising the motor examination of the Unified PD Rating Scale and neurologic examination and history taking by a research physician specialised in neurologic disorders to establish parkinsonism and to classify subtypes. Subjects who were suspected of having PD were invited for a further evaluation by a neurologist.

In addition to the in-person follow-up evaluation, the cohort was continuously monitored for detection of new cases of parkinsonism through a surveillance system by computer linkage with the general practitioners' automated medical record systems. Through this system, we were notified of incident cases of parkinsonism and had access to those subjects' medical records. If possible, a neurologist also examined these participants to confirm the diagnosis. We also used the information obtained from this surveillance system for subjects who could not be re-examined in person at follow-up evaluation (because of death, migration, disease, logistic reasons, or refusal). Furthermore, information on all participants who were prescribed antiparkinsonian drugs, identified by means of a computerised pharmacy database, was reviewed to check whether no cases had been missed.

Parkinsonism was diagnosed if 2 or more cardinal signs (e.g. resting tremor, rigidity, bradykinesia, or impaired postural reflexes) were present in a subject not taking antiparkinsonian drugs, or if in a person treated with antiparkinsonian medication, 1 or more signs, documented by medical history, had improved. PD was diagnosed if all causes of secondary parkinsonism, as well as dementia before the onset of parkinsonism, had been excluded.

The diagnostic criteria for the several subtypes of parkinsonism have been reported previously. In short, parkinsonism resulting from other causes included (1) parkinsonism associated with dementia (with dementia onset clearly preceding the onset of parkinsonism); (2) drug-induced parkinsonism (use of neuroleptics or other antidopaminergic drugs in the 6 months preceding the onset of symptoms and without history of parkinsonism); (3) parkinsonism related to cerebrovascular disease (with a clear time relationship between cerebrovascular event and onset of atypical parkinsonism, preferably supported by neuroimaging, usually without tremor); (4) parkinsonism in multiple system atrophy or progressive supranuclear palsy and (5) parkinsonism unspecified. Included in this latter category were subjects with more than one possible cause or with no clear time relationship between the possible cause and the onset of parkinsonism, as well as subjects in whom all other possible causes of parkinsonism could be excluded but who did not respond to antiparkinsonian drugs.

For the age at onset of $\mathrm{PD}$, we took the age at midpoint between the examination in which parkinsonism first was identified and the preceding examination. An objective indication of the time when the first symptom actually appeared is hard to achieve for all patients in an equally adequate way because PD has an insidious onset. Given the relatively short screening intervals, we considered age between 2 subsequent examinations to be a good approximation of the actual age at onset.'

\section{Explanation}

It is useful to know the severity of disease in the population being studied as this will enable the reader to compare the findings with their own patients with similar lev- els of disease severity. Any discordance in study findings could be due to the different levels of disease severity of the patients included. In many areas of neurology, there are several potentially useful instruments for assessing the severity of disease and thus instrument used for assessment should be reported [43]. The staging of the disease is important for neurodegenerative disease and although they share some characteristics, they are different because staging is based on when the diagnosis is made in the course of the natural history of the disease.

\section{7 (d) Basic Minimum Required Recommendation: Description of How Types/Subtypes of the Neurological Disorder of Interest Are Distinguished (If Relevant)}

\section{Example}

'Embolic or cardioembolic infarction was defined as mediumhigh-risk cardioembolic source, with less than $50 \%$ carotid stenosis or no vascular study. Large-vessel or atherothrombotic infarction was defined as carotid stenosis of $50 \%$ or more in the symptomatic side, without a high-risk cardiac source of emboli, or incomplete study. Small-vessel or lacunar infarction was identified as a small subcortical infarction or normal CT scan with typical lacunar syndromes, without a high-risk cardioembolic source, or carotid stenosis equal to or greater than $50 \%$.'

\section{Explanation}

If there are subtypes of the neurological disorder that have different aetiologies or courses, then it is important to report how these subtypes have been determined and defined so that the reader can compare the definitions used with their own study.

\section{7 (e) Basic Minimum Required Recommendation: Description of How Completeness of Case-Ascertainment Was Assessed}

\section{Example}

'Case-finding methods met the criteria for 'ideal' stroke incidence studies, utilising multiple overlapping sources. The major sources of case finding were the daily admission lists and stroke unit lists of the 17 major public and 28 private hospitals both within the study region and in the surrounding areas. Patients with a wide range of admitting diagnoses, including transient ischemic attack, were considered to be potential cases. To complement these 'hot pursuit' procedures, all hospitals provided computerised discharge lists of patients with ICD codes $430-438,342$ and 781 (9th revision) and codes I60-I69, G45, G81 and R25-R29.89 (10th revision). Surveillance at some public hospitals located outside the study area and most small private hospitals was by this 
means alone. Non-hospital sources were also surveyed rigorously. These included regular contact with general practitioners, physicians (165), neurologists (86), and geriatricians and rehabilitation specialists (47) practicing both inside and outside the study region, and monthly contact with managers of all 61 nursing homes and 56 hostels located within the study region. The study was also advertised in newsletters of the north east division of general practice and local newspapers. Finally, lists of patients in whom stroke was noted as either a primary or secondary cause of death were supplied by the Australian Bureau of Statistics. In these latter cases, further information was sought from hospital and nonhospital sources to determine eligibility. Potential cases were reviewed by a panel of stroke experts comprising between 2 and 4 stroke physicians and an epidemiologist. Clinical details of all potential cases were presented and panel consensus was required for inclusion.'

\section{Explanation}

For incidence and prevalence studies, it is important that all cases of the neurological condition have been ascertained within the predefined time-period. A description of how case-ascertainment was assessed will give the reader an indication of what sources were used to identify cases, whether there was overlap between the sources and what strategies were employed in order to determine the eligibility of cases for the study.

\section{7 (f) Ideal Reporting Recommendation: Description of whether Completeness of Case Ascertainment Was Adequate}

\section{Example}

'Patients were included in the French register of amyotrophic lateral sclerosis (ALS) in the Limousin region (FRALim) register if they lived in the Limousin region at the time of diagnosis of definite, probable, probable laboratory-supported or ALS according to El Escorial revised criteria and if they were identified by at least one of the sources below. The register used multiple sources of case ascertainment to identify incident cases. Diagnosis of ALS was made on clinical data and on results from electroneuromyography, which was systematically performed at the time of diagnosis. Case definition of ALS was uniform across sources, thanks to the review of all information by the same neurologist. The latter made the El Escorial revised criteria ascertainment.

A capture-recapture method was used to assess the exhaustiveness of case ascertainment. The total number of ALS cases and the independence of different sources were estimated by log-linear model analyses under the Poisson distribution using PROC GENMOD. Regarding the 3 sources, the model considered best was the one with the fewest interaction terms and that which best fitted the observed data (the lowest log-likelihood ratio statistic G2, Akaike information criterion and Bayesian information criterion (BIC)). The weighted BIC, in which the estimate of each model is weighted using the corresponding BIC, was also calculated. Calculations were performed overall and stratified by pe- riod (2000-2005 and 2006-2011). Based on a description of the characteristics of subjects identified or not for each source, it was possible to postulate potential differences in the likelihood of ascertainment by the sources depending on demographic or disease characteristics. This was taken into account in the best model by introducing interaction terms between sources and characteristics of the subjects (stratified analysis). Finally, corrected ALS incidence and estimations of the exhaustiveness of the different sources were calculated using the number of new cases of ALS during the study period estimated not to have been identified by any source.

Source 1 (ALS referral centres) identified 246 cases, source 2 (private and public hospitals) 249 and source 3 (health insurance) 152 . The median number of sources per subject was 2 (IQR 2-3); 129 cases were simultaneously reported by all 3 information sources. The goodness of fit of different log-linear models and estimates of the total number of new cases are summarised in table 3 . Analysis of the log-linear models revealed that the best model was that with 2 interaction terms (between S1 and S3, and between S2 and S3). The estimated number of subjects not identified by the multiple sources was 4.6 (95\% CI 2.4-8.8). For the period 2000 2005, it was 2.8 (95\% CI 1.1-7.4) and for 2006-2011, 1.9 (95\% CI 0.7-4.7). BIC weighted estimate was 2.6.'

\section{Explanation}

A description of whether the completeness of case-ascertainment was adequate will give the reader an indication of how many cases were potentially missed. This should enable the reader to gauge the reliability of the findings and the accuracy of the prevalence and incidence estimates. It is also important to discuss the method used to assess the adequacy of completeness of ascertainment along with how this was assessed and any assumptions made.

\section{Ideal Reporting Recommendation: Details of Ethical Approval/Informed Consent/Data Governance Should Be Reported}

\section{Example}

'Verbal and written consent was requested from the older adults selected, or alternatively, approval of their caregivers. All data collected in interviews was kept confidential. The study protocol was approved by the Ethics Committee of the Medical University of Havana.'

\section{Explanation}

The authors should have considered all of the ethical issues that are relevant to observational research involving human subjects when designing their study [44]. Any details about ethical approval required to conduct the study should be reported in the manuscript. 


\section{9 (a) Basic Minimum Required Recommendation: Incidence Studies (i) - Give Details of How Incidence Was Determined (Based on Timing of Data Collection either Prospectively or Retrospectively)}

\section{Example}

'Index cases were all residents of Iceland who were first diagnosed with an unprovoked seizure or epilepsy between December 1, 1995, and February 28, 1999. Epilepsy was defined in accordance with the 1993 International League Against Epilepsy criteria for epidemiological studies as recurrent unprovoked seizures (seizures occurring more than $24 \mathrm{~h}$ apart). In patients with newly diagnosed epilepsy, the first seizure might have occurred months or years before the study; these patients were included if there had been no previous medical diagnosis of epilepsy at the time of study presentation. People with a single unprovoked seizure were included in the study but were separately classified. Only definite diagnoses were included. Patients were excluded if they had only provoked (acute symptomatic) seizures including febrile seizures and neonatal seizures.'

\section{Explanation}

It is important that the reader knows all of the details of how incidence was defined for the particular neurological condition of interest, and whether these were first or recurrent events.

\section{9 (a) Basic Minimum required Recommendation: Incidence Studies (ii) - Definition and Justification of Timing of Measurements}

\section{Example}

'A first-ever stroke in a patient with a previous transient ischemic attack was coded as incident and a new stroke in a patient with a previous stroke was coded as recurrent. Neither new cases of 'transient ischemic attack' nor intracerebral haemorrhages were included in this study.'

\section{Explanation}

Definitions of a particular neurological condition can be variable so it is important that the reader of a manuscript can ascertain the exact inclusion and exclusion criteria being used and whether these criteria are similar to their own definitions.

\section{9 (a) Basic Minimum Required Recommendation: Incidence Studies (iii) - The Data Presented to Some Specified Time Period (Usually Whole Years or Person-Time)}

\section{Example}

'A total of 412 cerebral palsied children ( 258 boys and 154 girls) were born between 1984 and 2003 at Riyadh Military Hospital, Riyadh, Saudi Arabia. During this period, 99,788 live births were recorded. Information of the live-birth incidence was formed concerning only those children with cerebral palsy who were born in the study area during the specified period. Data were collected from the patients' files at the medical records department. The date of birth, study period, birth weight and aetiological classifications and definitions were employed in this study according to the classification of Hagberg et al.'

\section{Explanation}

It is important to know which time-period the incidence rate refers to, so that the reader of a manuscript can ascertain whether these results apply to a time period of relevance to their own needs (e.g. research or policy-making decisions).

\section{9 (a) Basic Minimum Required Recommendation: Incidence Studies (iv) - Raw Numbers Are Reported in Sufficient Detail (Tables, Figures or Main Text), to Calculate the Appropriate Rates (e.g. by Age or Gender)}

\section{Example}

'After comprehensive evaluation in all patients, ischemic stroke was diagnosed in 196 cases; 159 patients $(81.1 \%)$ with a first-ever ischemic stroke and $37(18.9 \%)$ a recurrent stroke. Fifty-one patients were excluded because of intracerebral haemorrhage $(n=50)$ or brain tumour $(\mathrm{n}=1)$, thus, a total of 196 patients with cerebral infarction were registered. Incidence rates and $95 \%$ CIs were calculated per 100,000 inhabitants. The denominator for the calculation of the incidence rate was the updated census data from the 2001 $(116,202$ inhabitants). Incidence rates were calculated for the whole population and by sex in the following age groups: $<45,45-49,50$ $54,55-59,60-64,65-69,70-74,75-79,80-84$ and $\geq 85$ years.'

\section{Explanation}

This is important so that the reader can replicate the findings. This information may also be useful to systematic review authors that wish to extract information from a paper for secondary analyses. Sudlow and Warlow suggest, in the context of stroke incidence studies, that investing a large amount of resources in case finding is inappropriate unless reliable and up-to-date information on the age and sex structure of the population is also available [37]. 
9 (b) Basic Minimum Required Recommendation:

Prevalence Studies (i) - Give Details of Specific Time

Points Over Which Estimates Are Derived (Usually

Defined as the Number of Cases Existing in a Specific

Time Point)

\section{Example}

'A validated self-administered headache questionnaire was mailed in June 2004 to a stratified random sample of 120,000 US households, drawn from a 600,000-household nationwide panel maintained by the National Family Opinion. A total of 120,000 households were contacted, encompassing 257,399 household members. Surveys were returned from 77,879 households $(65 \%$ response), yielding data for 162,576 household members aged 12 years or older. There were 18,968 individuals aged 12 years or older who met the second edition of the International Classification of Headache Disorders criteria for migraine yielding an unadjusted 1-year period prevalence estimate of $11.7 \%$ (5.6\% for men and $17.1 \%$ for women). Migraine prevalence was highest in those aged $30-39$ years for both men (7.4\%), and women $(24.4 \%)$. Prevalence was lowest in those aged 60 years or older at $1.6 \%$ in men and $5.0 \%$ in women. At the other end of the lifespan, prevalence was $4.0 \%$ in men and $6.4 \%$ in women aged between 12 and 17 years.'

\section{Explanation}

It is very important to know the details of the population size in the reported study in order to estimate prevalence rates accurately as well as the period that the prevalence estimate refers to.

\section{9 (b) Basic Minimum Required Recommendation: Prevalence Studies (ii) - The Data Presented to Some Specified Time Period (Usually in Whole Years)}

\section{Example}

'Total ascertainment of patients with recognised idiopathic PD in 9 municipalities with 220,000 inhabitants in the southern part of Rogaland County, western Norway, was attempted. Details of the case-finding procedure have been published elsewhere and are described briefly as follows. Clinical information on all patients with suspected parkinsonism was collected from the general physicians, nursing homes, district nurses, and home health care workers in the study area. After a screening procedure, 400 patients were invited to participate and were interviewed and examined by 1 of the neurologists in the study group. PD was diagnosed in 245 subjects, yielding a prevalence rate of 111 per 100,000 inhabitants on January 1, 1993. During followup, 7 subjects were re-diagnosed as not having PD (multiple system atrophy in 3, progressive supranuclear palsy in 1, and other neurodegenerative diseases in 3), leaving 238 patients eligible for our study.'

\section{Explanation}

A well-designed study enlists a sample that accurately represents a defined target population and presents data for a specified time period. This enables the comparison of the prevalence of the neurological condition across different populations for the same time period.

\section{9 (b) Basic Minimum Required Recommendation: \\ Prevalence Studies (iii) - Raw Numbers Are Reported \\ (in Tables, Figures or Main Text) in Sufficient Detail \\ to Calculate the Appropriate Rates (e.g. by Age or \\ Gender)}

\section{Example}

'In 2006, the crude prevalence of MS was 278.0 per 100,000 population. The age-adjusted prevalence was 226.7 (95\% CI 218.1235.3), and was higher in women than in men (RR 2.96; 95\% CI 2.71-3.24). Among women, the age-adjusted prevalence was 340.0 (95\% CI 325.3-354.6). Among men, the age-adjusted prevalence was 112.2 (95\% CI 103.4-121.0). Among women, the peak prevalence was observed among persons aged 45-59 years, about 10-20 years later than the peak incidence. Among men, the peak prevalence was observed among persons aged 55-69 years. With advancing age beyond these age groups, the prevalence declined steadily.'

'Stroke was reported in 104 individuals (19.1\% with 69.2\% female), while TIA was reported in 53 individuals (9.7\% with $69.8 \%$ female). Overall, stroke and/or TIA were found in 119 individuals (21.8\% with $66.4 \%$ females). The prevalence of stroke and TIA across gender, age groups and ethnicities is shown in table 2. Agestratified prevalence of stroke and TIA in males and females is presented in figure 2.'

\section{Explanation}

We recommend that the appropriate numbers in each age-sex strata be reported in order that the reader can ascertain how the rates were computed. It is useful to know the details of the population broken down by age and sex in the reported study, as these are generally the most useful information required for multiple stakeholders.

\section{9 (c) Ideal Reporting Recommendation: If Disease} Burden Is to Be Assessed the Study Should Report Details of Burden Due to a Variety of Sources (e.g. Disability, DALYs, Symptoms, Financial, Caregiver, etc.)

\section{Example}

'We identified patients with Duchenne muscular dystrophy (DMD) from Germany, Italy, United Kingdom, and United States through national DMD registries, which form part of the global Translational Research in Europe - Assessment and Treatment of Neuromuscular Diseases (TREAT-NMD) network. All 4 registries 
have been in operation for at least 7 years, ensuring good representation across age groups. To be eligible, patients were required to fulfill the following criteria: (1) male, (2) DMD diagnosis, and (3) age 5 years or older. Patients who were from Germany, Italy, United Kingdom, or United States but currently residing in a different country were not eligible for participation.'

Eligible patients and one of their caregivers (e.g. parent) were invited to complete a questionnaire online. The questionnaire consisted of questions regarding the patient (demographic information, health status, and DMD-related health care resource use) as well as the caregivers, their households, and DMD-related expenses. Recall periods were specified depending on the frequency of resource use in clinical practice and care guidelines, $(1$ month, 6 months, or 1 year). Patient and caregiver quality-of-life data were collected using the Health Utilities Index and EuroQol (EQ-5D) instrument, respectively. Study materials were presented in the native language of each country and subject to review by the TREAT-NMD coordination team to ensure understandability, accuracy, and completeness. A pilot study was conducted to further establish questionnaire validity. Recruitment started July 2012 and ended July 2013.'

\section{Explanation}

Disease burden is the impact of a health problem on a given area, and can be measured using a variety of indicators such as mortality, morbidity or financial cost. This allows the burden of disease to be compared between different areas, for example, regions. To assess a disease burden, the health impact of disease and injury needs to be assessed quantitatively at the population level. This may be measured in terms of the number of deaths, or as a summary measure of population health, such as the DALY [45]. While measurements of morbidity and mortality are key considerations for estimating the burden of disease in populations, they provide an incomplete picture of the adverse impact of ill health on human welfare. In particular, the economic consequences of poor health can be substantial. Analysis of the economic impact of illhealth addresses a number of policy questions concerning the consequences of disease or injury. Some of these questions relate to the microeconomic level of households, firms or government - such as the impact of ill-health on a household's income or a firm's profits - while others relate to the macroeconomic level, including the aggregate impact of a disease on a country's current and future gross domestic product [46]. Disease burden methodologies such as DALYs do not capture other aspects of disease and illness, such as pain and suffering, deterioration in quality of life, and emotional and physical impacts on families [47]. As a consequence, detailed information that describes when and how these aspects were assessed can be very important in a manuscript report.

\section{9 (d) Ideal Reporting Recommendation: Report Any Arrangements for Quality Checks/Data Verification/ Triangulation}

\section{Example}

'The National Hospital for Neurology and Neurosurgery (NHNN) is a referral centre for neurology in central London. A dedicated clinic was the basic of the facilitated link between general practice and the NHNN out-patients service. This was a general neurology clinic where only patients from the scheme were seen. Multiple methods of case-finding were used to ensure complete ascertainment. To check the sensitivity of the audit, a random selection of $2 \%$ of the notes was examined by an independent neurology trainee who was blind to the data already collected.'

\section{Explanation}

Independent assessment of a random sample of the data in order to check the quality and veracity of the overall data collected can be useful to identify any problems or issues with the data prior to finalisation [48].

\section{9 (e) Ideal Reporting Recommendation: Report \\ Details of the Training of the Person Administering \\ the Instruments}

Example

'A procedures manual was written covering all aspects of the study, including training and field procedures. The interviewers were 12 physicians, either clinical specialists or psychiatrists, who participated in the baseline study using the 10/66 protocol. All interviewers received 1 week of extensive training on the instruments and surveys to be applied.'

\section{Explanation}

It is very important to know if the data being collected from participants was done in a standardised manner in order to reduce the risk of information bias. Training of interviewers can reduce the likelihood of information bias occurring in the study.

\section{Basic Minimum Required Recommendation: If Rates Have Been Standardised (e.g. by Age or Gender), Then the Details of the Standard Population Used Should Be Given}

\section{Example}

'Table 4 provides age-adjusted prevalence rates per 1,000 populations for this study. The adjustments were made using both the US population 2,000 and the WHO new world population as the reference populations.' 


\section{Explanation}

The reader needs to know the details of the standard population used, so that the incidence or prevalence rates can be compared between independent studies [49].

\section{0 (a) Ideal Reporting Recommendation: If Possible \\ 2 Standard Populations Should Be Used One \\ with Local Relevance and the Other to Facilitate International Comparisons}

\section{Example}

'Incidence rates for Alzheimer's Disease (AD) were calculated by dividing the number of cases with onset of $\mathrm{AD}$ in each age group by the number of person-years of observation in that group. Since a majority of incident cases of dementia were accounted by AD (94\%), AD is reported as the primary outcome. Person-years were calculated from the time of study entry for each individual until the time of $\mathrm{AD}$ onset, or until the last date the subject was known to be non-demented (death, dropout, or most recent contact). The person-years method naturally accommodates both left truncation and right censoring. Incidence rates were also calculated within both gender categories and four age categories (55-59, 60-74, 75$79,80-84$, and $\geq 85$ years); $95 \%$ CIs around these rates were obtained based on Poisson distributions (appropriate for rare events).

In order to be able to compare with some of the published incidence rates in the western world and in the United States, we also calculated the age-adjusted incidence rate taking the US population of the year 2000 as the reference and the world age standardised rate taking the $\mathrm{WHO}$ world age standardised population 2000-2025.'

\section{Explanation}

It is very important to know how comparable the incidence or prevalence results for a study are to the local population (especially if trends over time are being presented) and it may also be useful to be able to say how internationally comparable the incidence or prevalence results of the study are with similar studies conducted elsewhere [50].

\section{0 (b) Basic Minimum Required Recommendation: Description of Any Assumptions Made in the Calculations Should Be Reported}

\section{Example}

'Data for estimating incidence rates were obtained from a US nationwide mailed survey of 163,186 individuals $\geq 12$ years of age participating in the American Migraine Prevalence and Prevention study. A self-administered questionnaire on headache was mailed to a stratified random sample of 120,000 US households, drawn from a 600,000-household nationwide panel maintained by the National Family Opinion, Inc.
The first method, labelled the 'naive' approach uses all available data and assumes that active migraine cases identified at crosssection include all individuals who have ever had migraine (i.e. no remission). For this approach, $n_{j}$ is the count of active migraine cases who reported onset in age interval $j$; $t_{j}$ is the sum of persontime for the $j$ th age interval contributed by those greater than or equal to age $j$ at interview and who had not reported migraine onset before the beginning of the $j$ th age interval. Individuals reporting migraine onset during the $j$ th age interval contribute persontime for only part of the age interval.

The second method uses data only from migraine cases who reported their onset to have occurred in the recent past. For the purposes of this analysis, recent onset was defined if an active case reported that their migraine first started within 3 years of the interview. In this approach, $n_{j}$ is confined to counts of active migraine cases who reported onset in the past 36 months and who reported it occurring in the $j$ th age interval; $t_{j}$ is defined as it is for the naive method, except that person-time is confined to individuals whose age at interview was within 3 years of the upper bound of the $j$ th age interval and who were migraine-free at any time during this age interval. There are 2 advantages to this method. First, errors in reporting age of onset are likely to be minimal. Second, complete remission of migraine among recent-onset cases is unlikely. We label this the 'diagonal' method. A disadvantage of this method is that the number of new-onset cases is limited and cannot be estimated for those $\leq 9$ years old.

The third method combines advantages of the naive (i.e. uses all data) and the diagonal (i.e. minimises bias) methods. Like the naive approach, data from all individuals were used to improve the precision of estimates. In contrast to the naive approach, regression methods were used to adjust for bias. Two sources of bias were of interest. Under-ascertainment occurs when a respondent forgets to report a history of severe headache or a cardinal migrainedefining symptom. Temporal reporting bias, which is another error, occurs when case status is accurately reported (i.e. no ascertainment bias), but age of onset is over- or underestimated.'

\section{Explanation}

Many incidence and prevalence studies use random sampling but some use complex sampling procedures. We recommend that authors clearly state the method or methods used to estimate prevalence or incidence and the impact of the complex sampling strategy so that readers may understand how the chosen sampling method influenced the precision of the obtained estimates of incidence or prevalence [29].

10 (c) Basic Minimum Required Recommendation: An Explanation of How Missing Data Was Addressed in the Analyses

\section{Example}

'We used multiple imputation to deal with missing data, which might lead to statistical power loss and bias. Multivariate regressions were used to generate 10 replacement values for each case of 
missing data, generating 10 imputed datasets using the STATA 'mi impute' command. The multivariate analyses used to assess the predictors of utility were then repeated by combining information from the 10 imputed datasets using STATA's 'micombine' command.'

\section{Explanation}

Missing data are common in observational research. Questionnaires posted to study participants are not always filled in completely and routine data sources and clinical databases are often incomplete. Any details of how missing data was dealt with by exclusion, simple imputation procedures or by more complex imputation procedures should be described in the report, as this gives the reader some idea of the reliability of the data [51]. Details of how many imputed datasets were generated and how they were combined with the details of the software used for these analyses can be helpful to the reader [52].

\section{0 (d) Ideal Reporting Recommendation: Provide a \\ Priori Estimates of: Sample Size/Power Assessment/ \\ Precision of Estimates Assessment}

\section{Example}

'Using a 95\% confidence, $5 \%$ estimated stroke prevalence reported previously and $2 \%$ bounds of error; a required sample size of 457 participants was calculated. Six hundred households were approached during the study period.'

\section{Explanation}

A study should be large enough to obtain a point estimate with a sufficiently narrow confidence interval to be able to meaningfully answer the research question of interest [53]. The importance of sample size determination in observational studies is context dependent and a formal sample size calculation may not always be necessary [54]. If a sample size calculation is given, the information should be reported in sufficient detail so that it can be reproduced by a statistically literate reader.

\section{0 (e) Basic Minimum Required Recommendation: \\ Description of Any Sensitivity Analyses}

\section{Example}

'To evaluate ascertainment bias that the use of different methodologies for African Americans and whites may have introduced (all minorities reviewed vs. screening for whites), data were used from the Pittsburgh site, in which all participants were reviewed, to estimate potentially missed cases in the entire Cognition Study cohort. In Pittsburgh, 12 of 319 (3.8\%) white participants were classified with dementia who would have been considered normal if screening had been done. Using this rate, the number of cases in whites that may have been missed at the other three sites was estimated.'

\section{Explanation}

Sensitivity analyses are useful to investigate the robustness of the main results to different analysis strategies or assumptions. The authors of manuscripts should clearly describe any alternative analyses or assumptions that they have made.

\section{The Results Section of the Report}

\section{Basic Minimum Required Recommendation: \\ Consider a Flow Diagram That Describes How \\ Participants Were Included in the Study (Useful in \\ Order to Assess How a Person with the Neurological \\ Condition of Interest Is Referred (with the Filters))}

Example

Llie epilepsy study: methodological approach.

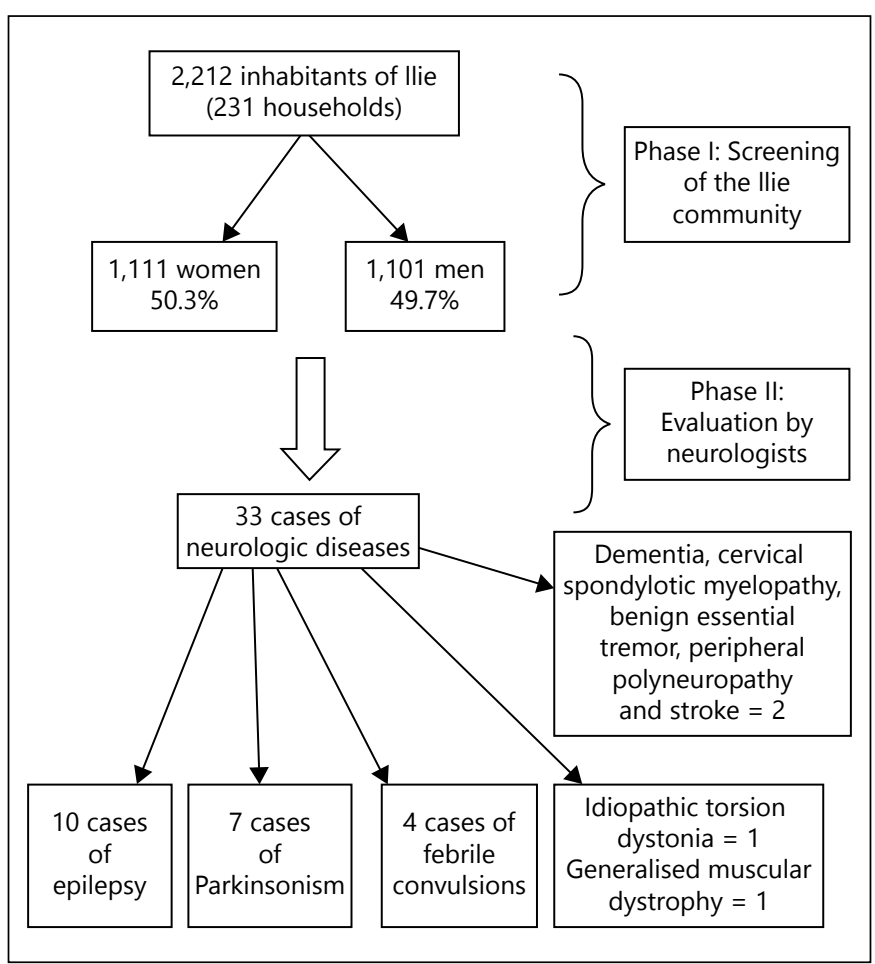

Reproduced with permission (receive 29 January 2015) from Elsevier publishers. 


\section{Explanation}

Detailed information on the process of recruiting study participants is important for several reasons. Those included in a study may differ in relevant ways from the target population to which results are applied. This may result in estimates of prevalence (or incidence) that do not reflect the experience of the target population. A well-structured flow diagram can be used to convey information in a clear and transparent manner that might otherwise require a lengthy description in the text.

\section{1 (a) Basic Minimum Required Recommendation:} Give Appropriate Rates with Their Associated 95\% CI

\section{Example}

'Among the 1,200 students 1,180 reported at least one headache attack (99.0\%; 95\% CI 98.3-99.5) and 44 had chronic daily headache (3.7\%). A total of 171 students fulfilled migraine criteria. The lifetime prevalence of migraine was $14.3 \%$ (95\% CI 12.3-16.4). Of the total number of students, 101 met criteria for aura with the frequency of $8.4 \%$.'

\section{Explanation}

In many situations, authors may present the results of unadjusted rates or age- and sex-adjusted rates. We also recommend that the estimates of rates should always be given with appropriate $\mathrm{CI}$, as this allows the reader to determine the precision of the estimates.

\section{1 (b) Basic Minimum Required Recommendation: Report Results of Any Sensitivity Analyses}

\section{Example}

'Whites with less than high school education had an age-adjusted dementia incidence (scaled to age 80 ) of 41.9 per 1,000 personyears, compared with 36.6 for high school graduates and 30.6 for individuals with at least some college education $(\mathrm{p}<0.001)$. Ageadjusted incidence of dementia for African Americans was 67.4 for those with less than high school, 55.8 for high school graduates, and 42.1 for college attendees $(p=0.79)$. Adjusted for age and education, a difference in dementia incidence by race was only of borderline significance $(\mathrm{p}=0.04)$.

To evaluate potential ascertainment bias, it was estimated that 56 of the 1,492 white participants in the group screened as normal could potentially have been missed dementia cases. Adding these estimated cases into those classified with dementia increased the number to 457 cases of dementia in whites. This translates into age-adjusted incidence rates of 58.8 per 1,000 person-years for whites, compared with 56.4 in African Americans.'

\section{Explanation}

The authors of manuscripts should clearly describe the impact of the alternative assumptions and analyses (that were conducted as part of the sensitivity analyses), on the main results.

\section{The Discussion Section of the Report}

\section{Basic Minimum Required Recommendation: Summarise the Key Findings in Relation to the Study Aims and Objectives}

\section{Example}

'This epidemiologic study summarises the prospectively collected data on more than 900 patients with acute TSCI who were admitted to our institution during the 10-year period from 1995 to 2004. In addition to characterising the temporal pattern of change for incidence rates, aetiology, spinal injury level, neurologic severity, treatment modalities, inpatient mortality, and hospital length of stay, we performed analyses to establish the effect of age and sex on these variables.

In our study, the annual incidence of TSCI ranged from 28.7 in 2003 to 43.4 per million in 1996. We reported age-standardised TSCI rates of 32.7 to 43.9 per million per year. For the population as a whole, this did not change significantly during the 10 -year study period. Spinal cord injuries are most frequent in young adults, especially in the age range of $18-24$ years, with the suggestion of a second peak in the 55- to 74-year-old age group, attributable specifically to falls from a standing height.'

\section{Explanation}

We recommend that the authors begin the discussion with a short summary of the main findings of the study. The short summary reminds readers of the key findings and will also facilitate the process of assessing whether the subsequent interpretation and inferences based on the key findings by the report authors are justified and are generally concordant with, or supported by, their findings.

\section{Basic Minimum Required Recommendation: Discuss Potential Limitations of the Study}

\section{Example}

'Head injury, unspecified' may also be responsible for the mTBI incidence spikes observed in the less than 5 and greater than 75-year-old age groups. The inability of ED providers to obtain an accurate history of LOC or amnesia in these age groups (either due to non-verbal status or dementia) may result in poor ED chart documentation for these variables which, in turn, forces coders to assign 'head injury, unspecified'. This is a limitation of the retrospective method used to generate administrative 
data. If encountered prospectively, many of these patients would not be classified as mTBI, but would have received an ICD-9-CM code outside of the definition (such as 873, Other Open Wound of the Head). Thus, these incidence spikes, especially the lessthan-5-year-old spike, may be artifactual. Another limitation of the administrative mTBI definition is that it relies on an interpretation of information documented by health care providers in the ED chart. Cases of mTBI that were clinically apparent to the health care providers in the ED setting may be missed by the ICD-9-CM definition because of poor ED chart documentation.'

\section{Explanation}

The authors should give an outline of the limitations of the study informing the reader about any weaknesses in the study design, any issues in the selection of participants, and any other key pieces of information that may have affected the study results.

\section{3 (a) Ideal Reporting Recommendation: Include Details of Risk of Bias (e.g. Selection Bias), Completeness of Case Ascertainment, and Data Quality (Assessment of Its Probability, Size and Potential Importance)}

\section{Example}

'Strengths of our study are the high linkage percentages and the large size of the cohorts. A high validity of both the hospital discharge registry (HDR) and the Dutch population registry (PR) has been demonstrated. In a random sample of the HDR, 99\% of the personal, admission and discharge data and $84 \%$ of the principal diagnoses were correctly registered. In a random sample of the PR, over $97 \%$ of the addresses were correctly registered and only $0.4 \%$ of days and months of birth were missing. Furthermore, over $97 \%$ of the uniquely linked hospital admissions resulting from linkage of the HDR with the PR were shown to be correctly linked and the estimated rate of mismatches (false positive linkages) was approximately $1 \%$.

With regard to underestimation of the incidence there are a number of issues that may need attention. First of all, the cause of death information used in our study was not validated against medical records or autopsy reports. Even though the validity of the Dutch register of causes of death is considered acceptable, it seems likely that some patients were misdiagnosed. Patients suffering from a stroke could be diagnosed with something else than stroke and patients diagnosed with something else than stroke could actually have been 'real' stroke cases. In addition, classification of stroke as cause of death appeared to be variable even among experienced vascular neurologists. However, studies estimating the degree of misclassification of stroke are not available. Secondly, the number of non-fatal, non-hospitalised patients younger than 65 years may have been underestimated as the results of the Rotterdam study could not be applied to this patient group and is therefore not taken into account in the estimations of the incidence.'

\section{Explanation}

It is important to discuss the relative importance, or impact of different biases, that may have been discussed as part of the limitations of the study. Issues such as completeness of case ascertainment, data quality and any selection or information biases should be addressed. Ideally the report should also attempt to quantify the likely direction and magnitude of any potential bias in the study [55]. Authors should also discuss any imprecision of the results, due to either study size or poor measurement due to diagnostic inaccuracy or quality of the data available.

\section{Basic Minimum Required Recommendation: Interpret the Results in the Context of the Evidence from Other Well Performed Studies with Similar Designs and Objectives}

\section{Example}

'We found a crude annual incidence rate of 7.93 per 100,000 inhabitants, which remained stable during the study period and was higher in women than in men. The rate was within the ranges reported from comparable registries, which varied from 7 to 13 per 100,000 in most geographical areas. Our rates were lower than those reported in Japan and in Finland, but higher than those reported in Central and South America. Differences might have been a result of the age distribution of the included patients, the different proportions of older people in the study populations and differences in the prevalence of arterial hypertension or genetic susceptibility. In contrast with ischemic and haemorrhagic stroke, whose rates progressively increased with age, the incidence of SAH showed an uneven age-related distribution in both sexes.'

\section{Explanation}

The main aim of the discussion section is the interpretation of the study results. The results should be put into context of other studies on the same topic and any potential reasons for discrepancies should be reported in order to explain this heterogeneity to the reader.

\section{4 (a) Basic Minimum Required Recommendation: Reliability of the Estimates (i.e. Based on the Reporting of the Statistical Methodology, and Study Design, Measurement of Key Information)}

\section{Example}

'To appreciate the findings there are number of critical aspects that need consideration. In this study, $15 \%$ of all first strokes are TIAs. However, TIAs are difficult to diagnose with confi- 
dence and misdiagnosing seems inevitable. Non-cerebrovascular diseases such as migraine and epilepsy may have been diagnosed as a TIA, while on the other hand, true TIAs may not have been recognised. However, studies estimating the degree of misdiagnosing are not available. With respect to overestimation of the incidence, the information on previous admissions was limited to a maximum of 5 years (as the numeric part of the postal code is registered in the hospital register since 1991). Therefore, it seems likely that some 'first-stroke' patients (especially those older than 65 years) were actually recurrent stroke patients (admission before 1991).'

\section{Explanation}

Due consideration should be given to confounding usually assessed by standardisation in incidence or prevalence studies and the robustness of the results to varying the assumptions (if sensitivity analyses have been performed). Authors should also consider residual confounding due to unmeasured variables or imprecise measurement of confounders if appropriate, and any issues with misclassification of the disease outcome. When interpreting results, authors should consider the potential sources of bias, including loss to follow-up and non-participation. It is not uncommon to see over-interpretation of the findings or unreasonable extrapolation beyond the limitations of the study design or the data presented [56].

\section{Basic Minimum Required Recommendation: Discuss the External Validity of the Study Findings}

\section{Example}

'Incidence rates of Motor neuron diseases (MND) in the General Practice Research Database (GPRD) were similar to those reported from previous prospective studies conducted in Europe, including population-based registries. This provides reassuring evidence that there was not an important degree of misclassification in the ascertainment of MND cases. The estimated rates in the GPRD were comparatively higher for individuals older than 75 years. Two possible mechanisms could explain this finding. First, it is possible that previous studies did not ascertain all cases in older individuals. Second, the computer diagnosis of MND in the GPRD may have a lower specificity among older individuals, which would increase the number of false positives. For example, in the Piemonte and Valle d'Aosta Register for Amyotrophic Lateral Sclerosis, the proportion of false positives for MND among hospitalised patients was higher among individuals 70 and older $(47 \%)$ than among younger patients (35\%). In the GPRD, we estimated the positive predictive value of the computer-based diagnosis to be $85 \%$ both in individuals younger than 70 years and in older individuals.'

\section{Explanation}

Knowledge of the population incidence and prevalence of the neurological disease can be helpful when applying results to other settings and populations. Generalisability, (also known as external validity or applicability), is the extent to which the results of a study can be applied to other circumstances. Basically what the reader needs to ascertain from the study report is: can results be applied to an individual, groups or populations that differ from those enrolled in the study with regard to age, sex, ethnicity, severity of disease, and comorbid conditions? Are the definitions of outcomes relevant to another setting or population? Are data that were collected in incidence or prevalence studies many years ago still relevant today? Are results from health services research in one country applicable to health systems in other countries? The question of whether the results of a study have external validity is often a matter of judgment that depends on the study setting, the characteristics of the participants, and the outcomes assessed [57]. Thus, it is crucial that authors provide readers with adequate information about the setting and locations, eligibility criteria, the definition of outcomes, and the period of recruitment and follow-up [57, 58]. The degree of non-participation, any key information on comorbidities and the health care system that is relevant to the study setting should be considered, as this can be useful when considering or making comparisons on the burden of the disease [59].

\section{5 (a) Basic Minimum Required Recommendation: \\ Are the Results Consistent with Meta-Analyses of \\ Descriptive Epidemiological Studies on the Same Topic \\ That Cover Different Settings (If Applicable)?}

\section{Example}

'The prevalence of epilepsy in various studies is not uniform worldwide including India. Hauser estimated the average prevalence rate of 5.2 per 1,000 population, based on 19 studies in different parts of the world. Sridharan and Murthy performed a metaanalysis of the prevalence data obtained from 20 communitybased studies on epilepsy in India. The overall age-adjusted prevalence rate was 533 per 100,000 populations ( $95 \%$ CI $425-$ 641), after correction for heterogeneity due to inter-study variation. The prevalence for urban areas was 510 per 100,000 (95\% CI 349-673), for rural areas 547 per 100,000 (95\% CI 404-690), and sex-specific prevalence showed 588 per 100,000 (95\% CI 389-787) among men and 551 per 100,000 (95\% CI 349-753) among women respectively. Our result also corroborated well with this metaanalysis.' 


\section{Explanation}

Consistency of results across a variety of setting promotes confidence in the findings and the external validity of the results. Meta-analysis provides an assessment of consistency, which is one of Bradford-Hill's criteria for causality in epidemiological studies [60]. This can be assessed through tests of heterogeneity and an assessment of differences across studies [61]. Meta-analyses can also provide an increase in the precision of effect estimates, including the precision of dose-response relationships. Large-scale meta-analyses of incidence or prevalence studies can be used to identify trends over time and have made a large contribution to the estimation of the global burden of disease for several neurological disorders [62-64].

\section{Concluding Remarks}

As the number of published neurological prevalence, incidence, and clinical studies in primary, secondary and tertiary care settings increase over time, we believe that standardised reporting of methods and findings will be increasingly important to facilitate interpretation and provide a means of comparing studies. We hope the STROND statement, consisting of 15 recommendations and an accompanying checklist will serve as a starting point for improving the standards of reporting. We believe it will be important to evaluate the effect of implementation of this statement and checklist on reporting in future incidence and prevalence studies of neurological conditions.

\section{Appendix 1}

The recommendations are entirely those of the members of the STROND collaborative group. All STROND members and Delphi process respondents are volunteers. We would like to thank the Delphi process respondents for participating in the process that led to the development of the reporting guideline.

\section{Core STROND Development Team}

Dr. Derrick A. Bennett (Nuffield Department of Population Health, University of Oxford, Oxford, UK); Professor Carol Brayne (Department of Public Health and Primary Care, University of Cambridge, Cambridge, UK); Professor Valery Feigin (National Institute for Stroke and Applied Neurosciences, AUT University, Auckland, New Zealand); Helen MacDonald (National Institute for Stroke and Applied Neurosciences, AUT University, Auckland, New Zealand).

\section{STROND Collaborators}

Professor Michael Brainin, Department for Clinical Medicine and Preventive Medicine, Danube-University Krems, Austria; Professor Pierre-Marie Preux, Institute of Tropical Neurology, University of Limoges, Limoges, France; Professor Peter Rothwell, Stroke Prevention Research Unit, University of Oxford, Oxford, UK; Dr. Pablo M. Lavados, Vascular Neurology and Stroke Unit, Neurology Service, Department of Medicine, Clínica Alemana de Santiago, Universidad del Desarrollo and Department of Neurological Sciences, Universidad de Chile, Institute of Neurosurgery, Santiago, Chile; Emeritus Professor of Neurology John F Kurtzke, Georgetown University, Washington, DC, USA; Dr. Suzanne Barker-Collo Department of Psychology, University of Auckland, New Zealand. Dr. Daniel Davis, Institute of Epidemiology and Health Faculty of Population Health Sciences, University College London, UK; Dr. Valentina Gallo, Centre of Primary Care and Public Health, Blizard Institute, Queen Mary, University of London, UK; Dr. Nathalie Jetté, Department of Clinical Neurosciences and Hotchkiss Brain Institute, Department of Community Health Sciences and O'Brien Institute for Public Health, University of Calgary, Canada; Dr. André Karch, Research Group Epidemiological and Statistical Methods, Helmholtz Centre for Infection Research, Braunschweig, Germany; Lawrence W. Svenson, School of Public Health, University of Alberta, Canada; Professor Giancarlo Logroscino, Neurodegenerative Diseases Unit, Department of Basic Medicine, Neurosciences and Sense Organs, University Aldo Moro, Bari, Italy; Gabriele Nagel, Institute of Epidemiology and Medical Biometry, University of Ulm, Ulm, Germany.

\section{References}

1 Glasziou P, Altman DG, Bossuyt P, Boutron I, Clarke M, Julious S, et al: Reducing waste from incomplete or unusable reports of biomedical research. Lancet 2014; 383:267-276.

2 Latronico N, Botteri M, Minelli C, Zanotti C, Bertolini G, Candiani A: Quality of reporting of randomised controlled trials in the intensive care literature. A systematic analysis of papers published in intensive care medicine over 26 years. Intensive Care Med 2002;28: $1316-1323$.
3 Lee CW, Chi KN: The standard of reporting of health-related quality of life in clinical cancer trials. J Clin Epidemiol 2000;53:451458.

4 Mallett S, Deeks JJ, Halligan S, Hopewell S, Cornelius V, Altman DG: Systematic reviews of diagnostic tests in cancer: review of methods and reporting. BMJ 2006;333:413.

5 Mills E, Loke YK, Wu P, Montori VM, Perri $\mathrm{D}$, Moher D, et al: Determining the reporting quality of RCTs in clinical pharmacology. $\mathrm{Br}$ J Clin Pharmacol 2004;58:61-65.
6 Pocock SJ, Collier TJ, Dandreo KJ, de Stavola BL, Goldman MB, Kalish LA, et al: Issues in the reporting of epidemiological studies: a survey of recent practice. BMJ 2004;329:883.

7 Bennett C, Khangura S, Brehaut JC, Graham ID, Moher D, Potter BK, et al: Reporting guidelines for survey research: an analysis of published guidance and reporting practices. PLoS Med 2010;8:e1001069.

8 PLOS Medicine Editors: Observational studies: getting clear about transparency. PLoS Med 2014;11:e1001711. 
9 Feigin V, Kurtzke JF, Korczyn A, Beghi E, Brown A: Bridging the gap between experimental and non-experimental neuroepidemiology, and ultimately - between neuroepidemiological research and practice: round table discussion at the first international congress on clinical neurology and epidemiology. Neuroepidemiology 2009;33: 296-304.

10 Campbell DM, Redman S, Jorm L, Cooke M, Zwi AB, Rychetnik L: Increasing the use of evidence in health policy: practice and views of policy makers and researchers. Aust New Zealand Health Policy 2009;6:21.

11 Murray CJ, Ezzati M, Flaxman AD, Lim S, Lozano R, Michaud C, et al: GBD 2010: a multiinvestigator collaboration for global comparative descriptive epidemiology. Lancet 2012; 380:2055-2058.

12 Feigin VL, Forouzanfar MH, Krishnamurthi R, Mensah GA, Connor M, Bennett DA, et al: Global and regional burden of stroke during 1990-2010: findings from the global burden of disease study 2010. Lancet 2014;383:245254.

13 Krishnamurthi RV, Feigin VL, Forouzanfar $\mathrm{MH}$, Mensah GA, Connor M, Bennett DA, et al: Global and regional burden of first-ever ischaemic and haemorrhagic stroke during 1990-2010: findings from the global burden of disease study 2010. Lancet Glob Health 2013;1:e259-e281.

14 Woldeamanuel YW, Andreou AP, Cowan RP: Prevalence of migraine headache and its weight on neurological burden in Africa: a 43year systematic review and meta-analysis of community-based studies. J Neurol Sci 2014; 342:1-15.

15 Stovner LJ, Hoff JM, Svalheim S, Gilhus NE: Neurological disorders in the global burden of disease 2010 study. Acta Neurol Scand Suppl 2014;198:1-6.

16 Murray CJ, Ezzati M, Flaxman AD, Lim S, Lozano R, Michaud C, et al: GBD 2010: design, definitions, and metrics. Lancet 2012;380 2063-2066.

17 Albert SM: Projecting neurologic disease burden: difficult but critical. Neurology 2007;68: 322-323.

18 Murray CJ, Vos T, Lozano R, Naghavi M, Flaxman AD, Michaud C, et al: Disability-adjusted life years (DALYs) for 291 diseases and injuries in 21 regions, 1990-2010: a systematic analysis for the global burden of disease study 2010. Lancet 2012;380:2197-2223.

19 Mateen FJ: Neurology and international organizations. Neurology 2013;81:392-394.

20 Benamer HT, Deleu D, Grosset D: Epidemiology of headache in Arab countries. J Headache Pain 2010;11:1-3.

21 Evans C, Beland SG, Kulaga S, Wolfson C, Kingwell E, Marriott J, et al: Incidence and prevalence of multiple sclerosis in the Americas: a systematic review. Neuroepidemiology 2013; 40:195-210.

22 Chin JH, Vora N: The global burden of neurologic diseases. Neurology 2014;83:349-351.
23 Danila O, Hirdes JP, Maxwell CJ, Marrie RA, Patten S, Pringsheim T, et al: Prevalence of neurological conditions across the continuum of care based on interRAI assessments. BMC Health Serv Res 2014;14:29.

24 Bennett DA, Brayne C, Feigin VL, Barker-Collo S, Brainin M, Davis D, et al: Development of the standards of reporting of neurological disorders (STROND) checklist: a guideline for the reporting of incidence and prevalence studies in neuroepidemiology. Eur J Epidemiol 2015;30:569-576.

25 Vandenbroucke JP, von Elm E, Altman DG, Gøtzsche PC, Mulrow CD, Pocock SJ, et al: Strengthening the reporting of observational studies in epidemiology (STROBE): explanation and elaboration. PLoS Med 2007;4:e297.

26 Leon AC, Davis LL, Kraemer HC: The role and interpretation of pilot studies in clinical research. J Psychiatr Res 2011;45:626-629.

27 Grimes DA: Epidemiologic research using administrative databases: garbage in, garbage out. Obstet Gynecol 2011;117:729-730.

28 Gavrielov-Yusim N, Friger M: Use of administrative medical databases in populationbased research. J Epidemiol Community Health 2014;68:283-287.

29 Beckett LA, Scherr PA, Evans DA: Population prevalence estimates from complex samples. J Clin Epidemiol 1992;45:393-402.

30 Benchimol EI, Manuel DG, To T, Griffiths AM, Rabeneck L, Guttmann A: Development and use of reporting guidelines for assessing the quality of validation studies of health administrative data. J Clin Epidemiol 2011;64: 821-829.

31 Benchimol EI, Guttmann A, Griffiths AM, Rabeneck L, Mack DR, Brill H, et al: Increasing incidence of paediatric inflammatory bowel disease in Ontario, Canada: evidence from health administrative data. Gut 2009;58: 1490-1497.

32 Guttmann A, Nakhla M, Henderson M, To T, Daneman D, Cauch-Dudek K, et al: Validation of a health administrative data algorithm for assessing the epidemiology of diabetes in Canadian children. Pediatr Diabet 2010;11 122-128.

33 Ahmed F, Janes GR, Baron R, Latts LM: Preferred provider organization claims showed high predictive value but missed substantial proportion of adults with high-risk conditions. J Clin Epidemiol 2005;58:624-628.

34 Jain S, Himali J, Beiser A, Ton TG, KellyHayes M, Biggs ML, et al: Validation of secondary data sources to identify Parkinson disease against clinical diagnostic criteria. Am J Epidemiol 2015;181:185-190.

35 St Germaine-Smith C, Metcalfe A, Pringsheim T, Roberts JI, Beck CA, Hemmelgarn $\mathrm{BR}$, et al: Recommendations for optimal ICD codes to study neurologic conditions: a systematic review. Neurology 2012;79:10491055.

36 Bruce M, Griffiths C, Brock A, Majeed A: Trends in mortality and hospital admissions associated with epilepsy in England and
Wales during the 1990s. Health Stat Q 2004; 21:23-29.

37 Rothwell PM: External validity of randomised controlled trials: 'to whom do the results of this trial apply?' Lancet 2005;365:82-93.

38 Altman DG, Bland JM: Generalisation and extrapolation. BMJ 1998;317:409.

39 Chowdhury RN, Hasan AT, Ur Rahman Y, Khan SI, Hussain AR, Ahsan S: Pattern of neurological disease seen among patients admitted in tertiary care hospital. BMC Res Notes 2014;7:202.

40 Draugalis JR, Coons SJ, Plaza CM: Best practices for survey research reports: a synopsis for authors and reviewers. Am J Pharm Educ 2008;72:11

41 Shakir R, Bergen D: International classification of diseases (ICD-11) and neurologic disorders: the future. Neurology 2013;81:182183

42 de Groot JA, Bossuyt PM, Reitsma JB, Rutjes AW, Dendukuri N, Janssen KJ, et al: Verification problems in diagnostic accuracy studies: consequences and solutions. BMJ 2011; 343:d4770.

43 Sheehan B: Assessment scales in dementia. Ther Adv Neurol Disord 2012;5:349-358.

44 Coughlin SS: Ethical issues in epidemiologic research and public health practice. Emerg Themes Epidemiol 2006;3:16.

45 Prüss-Ustün A, Bonjour S, Corvalán C: The impact of the environment on health by country: a meta-synthesis. Environ Health 2008;7:7.

46 WHO: Cost effectiveness and strategic planning (WHO-CHOICE). 2015. http://www. who.int/choice/economicburden/en/ (cited January 2015).

47 Thacker SB, Stroup DF, Carande-Kulis V, Marks JS, Roy K, Gerberding JL: Measuring the public's health. Public Health Rep 2006; 121:14-22.

48 Pandav R, Mehta A, Belle SH, Martin DE, Chandra V, Dodge HH, et al: Data management and quality assurance for an international project: the Indo-US cross-national dementia epidemiology study. Int J Geriatr Psychiatry 2002;17:510-518.

49 Naing NN: Easy way to learn standardization: direct and indirect methods. Malays J Med Sci 2000;7:10-15.

50 Zivadinov R, Iona L, Monti-Bragadin L, Bosco A, Jurjevic A, Taus C, et al: The use of standardized incidence and prevalence rates in epidemiological studies on multiple sclerosis. A meta-analysis study. Neuroepidemiology 2003;22:65-74.

51 Sterne JA, White IR, Carlin JB, Spratt M, Royston P, Kenward MG, et al: Multiple imputation for missing data in epidemiological and clinical research: potential and pitfalls. BMJ 2009;338:b2393.

52 Brick JM, Kalton G: Handling missing data in survey research. Stat Methods Med Res 1996; 5:215-238.

53 Bland JM: The tyranny of power: is there a better way to calculate sample size? BMJ 2009; 339:b3985. 
54 Vandenbroucke JP, von Elm E, Altman DG, Gøtzsche PC, Mulrow CD, Pocock SJ, et al: Strengthening the reporting of observational studies in epidemiology (STROBE): explanation and elaboration. PLoS Med 2007;4:e297.

55 Grimes DA, Schulz KF: Bias and causal associations in observational research. Lancet 2002;359:248-252.

56 Grimes DA, Schulz KF: False alarms and pseudo-epidemics: the limitations of observational epidemiology. Obstet Gynecol 2012; 120:920-927.

57 Rothman KJ, Greenland S: Validity and Generalizability in Epidemiologic Studies. Encyclopedia of Biostatistics, John Wiley and Sons, Ltd, 2005.
58 St Sauver JL, Grossardt BR, Leibson CL, Yawn BP, Melton LJ 3rd, Rocca WA: Generalizability of epidemiological findings and public health decisions: an illustration from the rochester epidemiology project. Mayo Clin Proc 2012;87:151-160.

59 Barnett K, Mercer SW, Norbury M, Watt G, Wyke S, Guthrie B: Epidemiology of multimorbidity and implications for health care, research, and medical education: a cross-sectional study. Lancet 2012;380:37-43.

60 Hill AB: The environment and disease: association or causation? Proc R Soc Med 1965;58: 295-300.

61 Stroup DF, Berlin JA, Morton SC, et al: Metaanalysis of observational studies in epidemi- ology: a proposal for reporting. JAMA 2000; 283:2008-2012.

62 Feigin VL, Lawes CM, Bennett DA, BarkerCollo SL, Parag V: Worldwide stroke incidence and early case fatality reported in 56 population-based studies: a systematic review. Lancet Neurol 2009;8:355-369.

63 Muangpaisan W, Hori H, Brayne C: Systematic review of the prevalence and incidence of Parkinson's disease in Asia. J Epidemiol 2009; 19:281-293.

64 Nevalainen O, Ansakorpi H, Simola M, Raitanen J, Isojärvi J, Artama M, et al: Epilepsyrelated clinical characteristics and mortality: a systematic review and meta-analysis. Neurology 2014;83:1968-1977. 